\title{
Treating glabellar lines with botulinum toxin type A-hemagglutinin complex:A review of the science, the clinical data, and patient satisfaction
}

This article was published in the following Dove Press journal:

Clinical Interventions in Aging

17 April 2010

Number of times this article has been viewed

\section{Koenraad De Boulle' \\ Steven Fagien ${ }^{2}$ \\ Boris Sommer ${ }^{3}$ \\ Richard Glogau ${ }^{4}$}

'Aalst Dermatology Clinic, Aalst, Belgium; ${ }^{2}$ Aesthetic Eyelid Plastic Surgery, Boca Raton, FL, USA;

${ }^{3}$ Aesthetic Dermatology, Frankfurt, Germany; ${ }^{4}$ University of California, San Francisco, USA
Correspondence: Koenraad De Boulle Aalst Dermatology Clinic, 43 Leopoldlaan, Aalst, Belgium 9300

Tel 3253781899

Fax 3253771915

Email koendeboulle@telenet.be

\begin{abstract}
Botulinum toxin type A treatment is the foundation of minimally invasive aesthetic facial procedures. Clinicians and their patients recognize the important role, both negative and positive, that facial expression, particularly the glabellar frown lines, plays in self-perception, emotional well-being, and perception by others. This article provides up-to-date information on fundamental properties and mechanisms of action of the major approved formulations of botulinum toxin type A, summarizes recent changes in naming conventions (nonproprietary names) mandated by the United States Food and Drug Administration, and describes the reasons for these changes. The request for these changes provides recognition that formulations of botulinum toxins (eg, onabotulinumtoxinA and abobotulinumtoxinA) are not interchangeable and that dosing recommendations cannot be based on any one single conversion ratio. The extensive safety, tolerability, and efficacy data are summarized in detail, including the patient-reported outcomes that contribute to overall patient satisfaction and probability treatment continuation. Based on this in-depth review, the authors conclude that botulinum toxin type A treatment remains a cornerstone of facial aesthetic treatments, and clinicians must realize that techniques and dosing from one formulation cannot be applied to others, that each patient should undergo a full aesthetic evaluation, and that products and procedures must be selected in the context of individual needs and goals.
\end{abstract}

Keywords: onabotulinumtoxinA, botulinum toxin type A, cosmetic, glabellar, patient satisfaction

\section{Moderate to severe glabellar lines: the rationale for treatment}

Perhaps Shakespeare's oft-quoted "There's no art to find the mind's construction in the face" (William Shakespeare. The Tragedy of Macbeth; Act I, Scene IV) might be amended to note that, although no simple art or science can determine the mind's construction from the face, facial expressions play complex and integral roles in interpersonal interactions and communication, self-perception and perception by others, and mood and emotional experience. ${ }^{1-11}$

Although researchers do not all agree that an individual's state of mind or emotion can be derived accurately from study of their facial expressions, the seminal work of Paul Ekman in the mid-1960s stimulated a wealth of research into the interpretation of facial expressions and the existence of feedback loops between emotional experience and expression, a concept attributed initially to Charles Darwin..$^{5,10}$ Briefly, this point of view hypothesizes that both negative and positive feelings can be modulated by the contraction of underlying facial musculature such as the zygomaticus. A number of

submit your manuscript | www.dovepress.com 
studies have provided evidence in support of this hypothesis. ${ }^{5}$ Recently, a small observational study indicated that patients who received botulinum toxin treatment of frown lines exhibited significantly improved mood. ${ }^{2}$ In contrast, the control group of patients who had received other minimally invasive cosmetic procedures or botulinum toxin treatment of crow's feet showed no such changes. Another small pilot study suggested that treatment of frown lines with botulinum toxin could help alleviate depression. ${ }^{12}$ These findings offer intriguing directions for larger, more systematic research.

\section{A brief history of turning back time with botulinum toxins}

Individuals have sought to improve their appearance throughout history and across virtually all cultures, quite possibly as long as our species has existed. ${ }^{13}$ Today's technology has made available an increasing array of options, both surgical and minimally invasive, to meet these desires and to maintain a more youthful appearance. Botulinum toxins have formed the foundation of minimally invasive aesthetic facial treatments, beginning with their use to smooth glabellar frown lines and expanding to include other facial areas as well as combination use with other minimally invasive agents and procedures.

The observation that botulinum toxin smoothed facial lines when used therapeutically led researchers to study the toxin's effect on glabellar frown lines. In 1992, the first published aesthetic study on botulinum toxin established that botulinum toxin type A safely and effectively diminished the appearance of glabellar lines. ${ }^{14}$ Additionally, largescale, randomized, controlled trials documented safety and efficacy, leading to the approval by the United States Food and Drug Administration (FDA) of the first botulinum toxin for cosmetic use in 2002. ${ }^{15}$ Recently, the FDA approved one additional botulinum toxin type A for cosmetic use. ${ }^{16}$ Worldwide, these two formulations are the main neurotoxins currently approved by various regulatory authorities for the treatment of moderate to severe glabellar lines, although other type A formulations, particularly NT-201, have received some approvals for cosmetic use in a few countries. Other injectable botulinum toxins, as well as a topical formulation, have been studied or are currently undergoing investigation in cosmetic and related indications. ${ }^{17-19}$

This review will examine these changes, will briefly examine the basic similarities and differences among available botulinum toxins, will summarize the key safety and efficacy data, and will discuss the implications for clinical practice.

\section{The science of botulinum toxins: composition and pharmacology}

Botulinum toxins occur in 7 known serotypes labeled A-G produced by different strains of Clostridium botulinum. ${ }^{20,21}$ Clinically important biologic activity, particularly in the cosmetic arena, is limited primarily to the type A serotype, although a type $\mathrm{B}$ formulation is approved in several countries for treating cervical dystonia. ${ }^{21,22}$ Although botulinum toxin type B has been studied for cosmetic use, it generally elicits more pain upon injection and has been found to have a faster onset but shorter duration of action than the type $A$ serotype. ${ }^{17,18,23-25}$ Therefore this review will be restricted to products containing botulinum toxin type A.

Similarities and differences among these botulinum toxins have been reviewed from preclinical and clinical perspectives, and readers are referred to some of these publications

Table I Comparisons among approved botulinum toxins

\begin{tabular}{llll}
\hline & OnabotulinumtoxinA & AbobotulinumtoxinA & NT-20I \\
\hline Company & Allergan, Inc. & Ipsen Inc./Medicis Inc. & Merz Pharmaceuticals \\
Type & Type A-Hall strain & Type A-Hall strain & Type A-Hall strain \\
Approvals (depend on specific & In more than 75 countries & In more than 65 countries, & Germany, other European countries, \\
indications) & worldwide, including United States & including United States & Mexico, Argentina, Brazil \\
& and Canada & and Canada & \\
Active substance (molecular & Botulinum toxin type A complex & Botulinum toxin type A & Botulinum toxin type A, free from \\
weight) & $(900 \mathrm{kDa})$ & complex $(500 \mathrm{kDa})^{\mathrm{a}}$ & complexing proteins (I50 kDa) \\
Indications & Blepharospasm; cervical & Blepharospasm; cervical & Blepharospasm; cervical dystonia; \\
& dystonia; glabellar lines; hyperhidrosis & dystonia; glabellar lines & cosmetic use in some countries \\
Mode of action & SNAP-25 & SNAP-25 & SNAP-25 \\
Units/vial & 100 & 300 or 500 & I00
\end{tabular}

Notes: SNAP-25 (synaptosomal membrane-associated protein with the molecular mass of $25 \mathrm{kDa}$ ) =An intracellular protein that is essential for synaptic vesicle transmission; it has been identified as the molecular target of botulinum toxin type A. ${ }^{\text {TT }}$ The formulation contains complexes of variable size between $500 \mathrm{kDa}$ and $900 \mathrm{kDa}$. Reproduced with permission from Carruthers A, Carruthers J. Botulinum toxin products overview. Skin Therapy Lett. 2008; 13(6): I-4. ${ }^{22}$ 
for additional, detailed, information. ${ }^{22,26-35}$ Basic properties of each product are summarized in Table $1 .{ }^{22}$ All botulinum toxins ultimately inhibit the release of acetylcholine from the neuromuscular junction and inhibit muscular contraction. ${ }^{27}$ Type A botulinum toxins cleave a protein called synaptosomal membrane-associated protein $25 \mathrm{kDa}$ (SNAP-25). The active neurotoxin is $150 \mathrm{kDa}$, but the currently available formulations differ in their molecular weight because of the presence or absence of complexing proteins. The nontoxin proteins of the two forms of botulinum toxin type A approved in the United States for aesthetic indications each include a hemagglutinin..$^{20}$ The two nonproprietary names for the currently FDA approved botulinum toxin type A products are onabotulinumtoxinA and abobotulinumtoxinA.

It has been suggested that the specific properties of each botulinum toxin may account in part for observed differences in clinical performance. For example, preclinical data indicate that the $500 \mathrm{kDa}$ and $900 \mathrm{kDa}$ have nonparallel dose-responsive curves, which means that their relative performance is not consistent across a range of dose ratios and that a given unit of one toxin does not stand in a constant unit relationship to another toxin. ${ }^{36}$ Clinically, some investigators have observed differences in migration patterns for the two products, although others have taken issue with these findings. ${ }^{37-39}$

It is likely that differences among products in these studies are influenced by the specific dose ratios used. ${ }^{40}$ In this study the field of effectiveness in the frontalis muscles at 28 and 112 days after injection of 2 botulinum toxin type As at 2dose ratios, abobotulinumtoxin $\mathrm{A}$ and onabotulinumtoxin $\mathrm{A}$ did not differ with respect to any effects at a dose ratio of 2:1 (abobotulinumtoxinA:onabotulinumtoxinA). At a dose ratio of 2.5:1, however, the effect of abobotulinumtoxin $A$ was more widespread (field of effectiveness) than was that of onabotulinumtoxinA. The data overall confirm that formulations of botulinum toxins are not interchangeable, nor can they be converted by a single dose conversion factor.

Data on formulations without complexing proteins have not been published in this context at this point. It has also been suggested that differences in the amount of nontoxin protein could contribute to differences in the likelihood of immunogenic reactions, but thus far, clinical data are lacking. Virtually no antibody formation nor loss of efficacy has been found in cosmetic studies with botulinum toxin type A. ${ }^{41,42}$ The most important point regarding the differences in botulinum toxin formulations is that clinicians must understand that botulinum toxins are not identical because of an array of factors, and are therefore not interchangeable. Thus, it is essential to understand the properties and clinical performance of each product in order to achieve safe and satisfactory outcomes.

\section{Distinguishing among botulinum toxins: revised labeling from the FDA}

In response to reports of some serious adverse events (SAEs), the FDA announced label changes for all botulinum toxins in April 2009, which resulted in the addition of a boxed warning to call attention to the possibility that treatment with a botulinum toxin has the potential to cause symptoms similar to those of botulism.

Notably, the press release issued by the FDA stated that symptoms have mostly been reported in children with cerebral palsy who have been treated for muscle spasticity, an unapproved use. The release also emphasized that the action was taken "because of the potential for serious risks associated with the lack of interchangeability among the three licensed botulinum toxin products. ${ }^{" 16}$ In addition, the FDA mandated a Risk Evaluation and Mitigation Strategy (REMS) to help clinicians understand risks and benefits, and to communicate these to their patients ${ }^{43}$ for all botulinum products. Prescribing information now includes an approved Medication Guide for patients. ${ }^{44}$

These additional changes to botulinum toxin product labeling have underscored how important it is to recognize that toxins are not interchangeable, and to incorporate this consideration into practice. Previous product labeling for botulinum toxins stated that formulations are not interchangeable because of differences in assays, laboratory protocols, and specifics of the manufacturing processes. Nevertheless, the original nonproprietary (established) named products were derived from a single serotype, such as botulinum type A, failed to distinguish among the products. Subsequent to the announcement of the labeling changes noted above, the FDA also issued changes to the established names for 4 products licensed in the United States (Table 2). ${ }^{43}$ Taken together, these changes indicate clearly that clinicians must develop expertise with each product they choose to use, and determine its optimal use in their individual practices even though each has been designated as safe and effective for the approved indications.

\section{Safety and efficacy - from clinical trials to clinical experience}

Since the effects of botulinum toxin type A on glabellar lines were first appreciated, safety and efficacy have been 
Table 2 New and old drug names for botulinum toxins in the United States; tradenames have not changed ${ }^{43}$

\begin{tabular}{|c|c|c|}
\hline New drug name & Old drug name & Indication(s) \\
\hline Onabotulinumtoxin $\mathrm{A}$ & $\begin{array}{l}\text { Botulinum toxin } \\
\text { type } \mathrm{A}\end{array}$ & $\begin{array}{l}\text { Cervical dystonia, } \\
\text { severe primary axillary } \\
\text { hyperhidrosis, strabis- } \\
\text { mus, blepharospasm; } \\
\text { temporary improve- } \\
\text { ment in the appearance } \\
\text { of moderate to severe } \\
\text { glabellar lines }\end{array}$ \\
\hline AbobotulinumtoxinA & $\begin{array}{l}\text { Botulinum toxin } \\
\text { type A }\end{array}$ & $\begin{array}{l}\text { Cervical dystonia, } \\
\text { temporary improve- } \\
\text { ment in the appearance } \\
\text { of moderate to severe } \\
\text { glabellar lines }\end{array}$ \\
\hline RimabotulinumtoxinB & $\begin{array}{l}\text { Botulinum toxin } \\
\text { type B }\end{array}$ & Cervical dystonia \\
\hline
\end{tabular}

supported and documented by numerous studies as well as extensive clinical experience. As an overview, virtually all large-scale studies, documenting safety and efficacy, are placebo-controlled, but are noncomparative. The primary efficacy endpoint for the majority of clinical studies has been based on changes on a 4-point scale of wrinkle severity ( $0=$ none, $1=$ mild, $2=$ moderate, $3=$ severe $)$, sometimes termed the Facial Wrinkle Scale. ${ }^{42,45}$ Typically, responders are those who are rated as 0 or 1 posttreatment as evaluated by an investigator, trained observer, or independent assessor. Unless noted otherwise, responder rates presented herein will be the proportion of subjects rated by investigators as none or mild at maximum frown. Trials have also included investigator- and subject-assessed global improvement, duration of response, subject satisfaction, and other patient-reported outcomes (PROs), which will be reviewed briefly in separate sections. Note that onset of action cannot be derived from any of the pivotal studies because they were not designed to do so, and the earliest assessment times were at 7 days with onabotulinumtoxin $\mathrm{A}^{45}$ and 14 days with abobotulinumtoxin $\mathrm{A} .{ }^{42}$ Older data on onabotulinumtoxinA indicate that response onset with onabotulinumtoxinA is within the first 24 to 72 hours, ${ }^{46}$ which is consistent with its product labeling regarding chemical denervation of injected muscles. ${ }^{45}$ A number of studies, reports, and consensus publications have also helped refine dosing and techniques and establish guidelines for optimizing results.

\section{Primary safety and efficacy studies}

FDA regulatory approvals of onabotulinumtoxinA and abobotulinumtoxinA were based on well-controlled studies in the treatment of moderate to severe glabellar lines. ${ }^{42,45}$ To the authors' knowledge, another botulinum toxin type A formulated without complexing proteins has not been studied systematically in cosmetic indications. A report based on clinical experience suggests that it is active for these uses, but controlled clinical trials remain to be reported..$^{47}$ Despite the addition of the previously cited warning to the prescribing information of all botulinum toxins approved in the United States, the use of these substances worldwide in facial aesthetics is associated with a remarkable record of safety and tolerability when used as indicated by fully qualified, welltrained clinicians. Not only do clinical studies report that AEs are typically transient and mild to moderate in severity, vast clinical experience and the increase in the number of procedures performed annually is highly confirmatory. It would be beyond the scope of this article to evaluate safety in all published articles on botulinum toxins, and therefore only the results of registration trials and selected long-term studies for the 2 major formulations of botulinum toxin type A are presented.

\section{Safety based on registration trials in the United States}

OnabotulinumtoxinA was approved in 2002 by the FDA to temporarily improve the appearance of moderate to severe glabellar lines in adult patients aged 18 to 65 years on the basis of 2 placebo-controlled, randomized clinical trials. ${ }^{15,41,42,45}$ Subjects $(\mathrm{N}=537)$ had to have glabellar lines of at least moderate severity at maximum frown to be eligible. ${ }^{41}$ They received either $20 \mathrm{U}$ of onabotulinumtoxinA $(\mathrm{n}=405)$ or an equal volume of placebo $(n=132)$ distributed equally among 5 injection sites. Most of the subjects were Caucasian $(84 \%)$ females $(82 \%)$. Because the 2 trials were identical in design, results were pooled and presented in their entirety along with an 8-month open-label extension. ${ }^{41,45}$

Treatment-related AEs declined with successive treatments (Table 3). ${ }^{41}$ The 2 most frequently occurring, treatment-related AEs, headache and blepharoptosis, diminished to less than $1 \%$ after the third treatment. The investigators suggested that this change could have resulted from improved injection skill, better understanding of the specifics of treating an individual patient, or the possibility of tolerance development. Subjects who received 3 injections of onabotulinumtoxinA were also tested for neutralizing antibodies. None of these patients tested positive for neutralizing antibodies. Although 4 subjects had positive tests after one of their treatments, all had negative tests after 1 year of treatment and remained responders. 
Table 3 Incidence of the most common ${ }^{\mathrm{a}}(>1 \%$ in any treatment cycle) treatment-related AEs by treatment cycle with onabotulinumtoxinA

\begin{tabular}{llll}
\hline Adverse event, \% & First botulinum toxin $(\mathbf{n}=\mathbf{5 0} \mathbf{I})$ & Second botulinum toxin $(\mathbf{n}=\mathbf{3 6 2})$ & Third botulinum toxin $(\mathbf{n}=\mathbf{2 5 8})$ \\
\hline Headache & 8.2 & 0.6 & 0.8 \\
Blepharoptosis & 3.0 & 2.2 & 0.8 \\
Face pain & 1.8 & 0.0 & 0.0 \\
Edema at injection site & 1.4 & 0.8 & 0.4 \\
Pain at injection site & 1.4 & 0.8 & 0.0 \\
Nausea & 1.2 & 0.0 & 0.0 \\
Ecchymosis & 1.2 & 0.0 & 0.0 \\
Muscle weakness & 1.4 & 0.3 & 0.0 \\
Erythema & 1.6 & 0.0 & 0.0 \\
\hline
\end{tabular}

alncidence $>1 \%$ in any treatment cycle.

Carruthers A, Carruthers J, Lowe NJ, et al; for the BOTOX ${ }^{\circledR}$ Glabellar Lines I and II Study Groups. One-year, randomised, multicenter, two-period study of the safety and efficacy of repeated treatments with botulinum toxin type A in patients with glabellar lines.J Clin Res. 2004;7: I-20. ${ }^{41}$ @ 2004 Informa Healthcare. Reproduced with permission.

In 2009, the FDA approved abobotulinumtoxinA to temporarily improve the appearance of moderate to severe glabellar lines (also based on the 4-point wrinkle severity scale) in adult patients younger than 65 years of age on the basis of 3 double-blind randomized studies, with a total of 600 subjects. $^{42,43}$ In each trial, subjects received $50 \mathrm{U}$ of abobotulinumtoxin A, based on results from previous studies which indicated this to be the optimal dose. ${ }^{48,49}$

Like onabotulinumtoxinA, abobotulinumtoxinA was well tolerated in clinical studies. ${ }^{42}$ The safety population for which AEs were reported comprised 894 subjects (abobotulinumtoxinA, 398; placebo, 496). Some of these subjects may have received both active treatment as well as placebo at different periods of study. Low rates of eye disorders, including ptosis $(2 \%$ in active treatment, $1 \%$ placebo) occurred, did not increase with treatment, and were generally mild to moderate in severity, resolving over several weeks. ${ }^{42}$ The development of neutralizing antibodies was also low. It was reported that 1554 of subjects in the entire safety database received up to 9 cycles of treatments, and only 3 tested positive for antibodies posttreatment. ${ }^{42}$

\section{Longer-term safety with repeated treatments}

Extensive clinical experience indicates botulinum toxin used for facial aesthetic treatment to be safe and well tolerated over the long term. Several studies have reported safety profiles over repeated treatments or over the longer term in clinical practice. A retrospective single center analysis provided data on 853 treatment sessions in 50 patients treated with onabotulinumtoxinA (median dose, $40 \mathrm{U}$ ). ${ }^{50}$ Patients were required to undergo a minimum of 10 treatments (range 10-30). The time period between the first and last treatments ranged from nearly 3 years to approximately 9 years. More than 50\% of the sessions involved treatment of more than one upper facial area, although treatment of the glabellar area predominated. The median interval between treatments was 17 weeks. Of all the treatments, 99\% did not result in any AEs. Altogether, 8 of the 50 subjects experienced 10 AEs. Of the 10 events, 5 were deemed treatment-related: bilateral eyebrow ptosis (2); right brow ptosis (1); right eyelid ptosis (1); and dysphagia (1). All were mild in severity and transient. The incidence of ptosis was approximately $0.47 \%$ /session.

A repeated treatment study of up to 5 cycles was conducted in Japanese subjects. ${ }^{51}$ Subjects received either $10 \mathrm{U}$ $(n=180)$ or $20 U(n=183)$ of onabotulinumtoxinA. They could be retreated at the same dose only if at least 12 weeks had elapsed and if glabellar line severity had returned to at least moderate. Responder rates did not diminish over treatment cycles, nor did any blood samples yield a positive test for neutralizing antibodies. Blepharoptosis occurred in $3.9 \%$ of subjects with no significant differences between treatment groups for this or any other AE deemed to be drug related.

A retrospective chart review was also undertaken in 945 abobotulinumtoxinA-treated patients treated over 3 to 5 consecutive cycles. ${ }^{52}$ Glabellar lines were treated in the vast majority of sessions, although most patients received treatment of multiple upper facial areas. The median total dose/session was $100 \mathrm{U}$. Approximately 91\% of patients experienced no AEs. A total of 16 patients experienced 19 instances of lid or brow ptosis $(0.51 \% /$ treatment cycle for patients receiving glabellar and/or frontalis treatments). These excellent safety results are thus comparable to those with onabotulinumtoxinA. 
Recently, interim safety results of an open-label extension trial using 6 repeated treatments of abobotulinumtoxinA for moderate to severe glabellar lines over 17 months with a minimum of 85-day intervals were reported. ${ }^{53}$ Of the 768 subjects, 2259 treatments had taken place, with $63 \%$ of subjects receiving up to 3 injections. At the time of analysis, $0.9 \%$ of subjects had received 6 treatments. Treatmentemergent AEs decreased over cycles. In total, 10 subjects (1.3\%) had 10 instances of ptosis in the 2259 treatments. The duration of these episodes was less than 3 weeks in $70 \%$ of the cases. Similar findings were reported for an analysis of 1200 subjects who had received up to 5 treatments within a 13 -month period. ${ }^{54}$

\section{Meta-analysis of onabotulinumtoxinA safety in global registration trials}

In a recent study, the results of 6 randomized, double-blind, placebo-controlled trials and 3 open-label studies were subjected to a meta-analysis. Comprising 1678 subjects, the results confirmed the safety and tolerability of onabotulinumtoxinA treatment for the glabellar and crow's feet areas. ${ }^{55}$ SAEs were generally mild to moderate in severity and in line with the expected AEs for this product. Importantly, no SAEs were detected, nor did any new, treatment-related AEs emerge. Taken together, the results demonstrate that these 2 formulations of botulinum toxin type $\mathrm{A}$, onabotulinumtoxin $\mathrm{A}$ and abobotulinumtoxinA, are safe and well tolerated based on both shorter- and longer-term studies.

\section{Efficacy with onabotulinumtoxinA}

In the pooled pivotal trials of onabotulinumtoxinA conducted in 537 subjects, the primary efficacy endpoints were the investigator's rating of glabellar line severity and the subject's global assessment of change in appearance at day 30 posttreatment. According to investigator ratings, the peak responder rate of $80 \%$ was observed at day 30 , but $25 \%$ of subjects remained classified as responders at day 120 (Figure 1a). ${ }^{45}$ Subject ratings followed a similar pattern with an $89 \%$ subject-rated responder rate at day 30 and $39 \%$ at day 120 (Figure 1 b). ${ }^{45}$ Subjects were able to receive a second, open-label treatment after completing the blinded study period of 120 days. A third injection option was also available, and 258 subjects received all 3 treatments. The proportion of responders at maximum frown was significantly higher after the second and third treatments than at the same time point after the first treatment (Figure 2). ${ }^{41}$

\section{Efficacy with abobotulinumtoxinA}

In the abobotulinumtoxinA trials, treatment success was evaluated at day 30 and was defined as glabellar line severity of none or mild at maximum frown, with at least a 2-grade improvement from baseline in the combined assessments of investigators and subjects. ${ }^{42}$ Treatment success ranged from $55 \%$ to $60 \%$ with abobotulinumtoxinA $(n=376)$ compared to $0 \%$ with placebo $(n=224)$ across the 3 studies. In addition, percentages of subjects achieving investigator- or subject-assessed ratings of none or mild at each posttreatment follow-up visit were also presented for each study (Figure 3). ${ }^{56}$ These results are similar to those seen with onabotulinumtoxinA, although it is obviously not possible to compare directly between studies.

\section{Additional clinical studies OnabotulinumtoxinA}

A registration trial with onabotulinumtoxinA treatment of glabellar lines in Japanese subjects was also conducted. ${ }^{57}$ In this study, 140 subjects with moderate to severe glabellar lines at baseline were treated with either $10 \mathrm{U}(\mathrm{n}=45)$ onabotulinumtoxinA, $20 \mathrm{U}(\mathrm{n}=46)$ onabotulinumtoxinA, or placebo $(n=49)$. The percentage of responders (rated none or mild) ranged from $82 \%$ and $89 \%$ at week 1 to $24 \%$ to $32 \%$ at week 16 for the $10-\mathrm{U}$ and $20-\mathrm{U}$ doses, respectively. Peak responses occurred at week 4 with $86 \%$ and $89 \%$ of subjects in the two groups rated as responders. Each dose differed significantly from placebo, but not from each other at each time point although the $20-\mathrm{U}$ dose was consistently associated with slightly higher responder rates. In a repeated treatment study of a similar population, 363 subjects received up to 5 treatments with onabotulinumtoxinA. ${ }^{51}$ Peak responder rates ranged from $92 \%$ to $99 \%$ at the week 4 evaluation of each of the 5 possible treatment cycles, indicating no diminution of efficacy over the 64 weeks of this trial. ${ }^{51}$

Consistent with clinical experience, dose-ranging studies established that males typically require higher doses than females of onabotulinumtoxinA, owing to their typically greater muscle mass. ${ }^{58,59}$ For males ( $\mathrm{N}=80,20$ /group), the peak responder rate occurred between weeks 2 and 4 posttreatment and was $65 \%$ in the 20 -U group compared to $100 \%$ in the other groups $(40 \mathrm{U}, 60 \mathrm{U}, 80 \mathrm{U}) .{ }^{58}$ Generally, the higher the dose, the longer the duration of the response, with a mean time to relapse (return to baseline severity on 2 consecutive visits, 30 days apart) of 24.2 weeks for the $80-\mathrm{U}$ dose compared to 17.6 weeks for the $20-\mathrm{U}$ dose.

In a similar study in females, subjects $(\mathrm{N}=80,20$ /group) received onabotulinumtoxinA doses of $10,20,30$, or $40 \mathrm{U}$ to their moderate to severe glabellar lines. ${ }^{59}$ The $10-\mathrm{U}$ dose was 
A

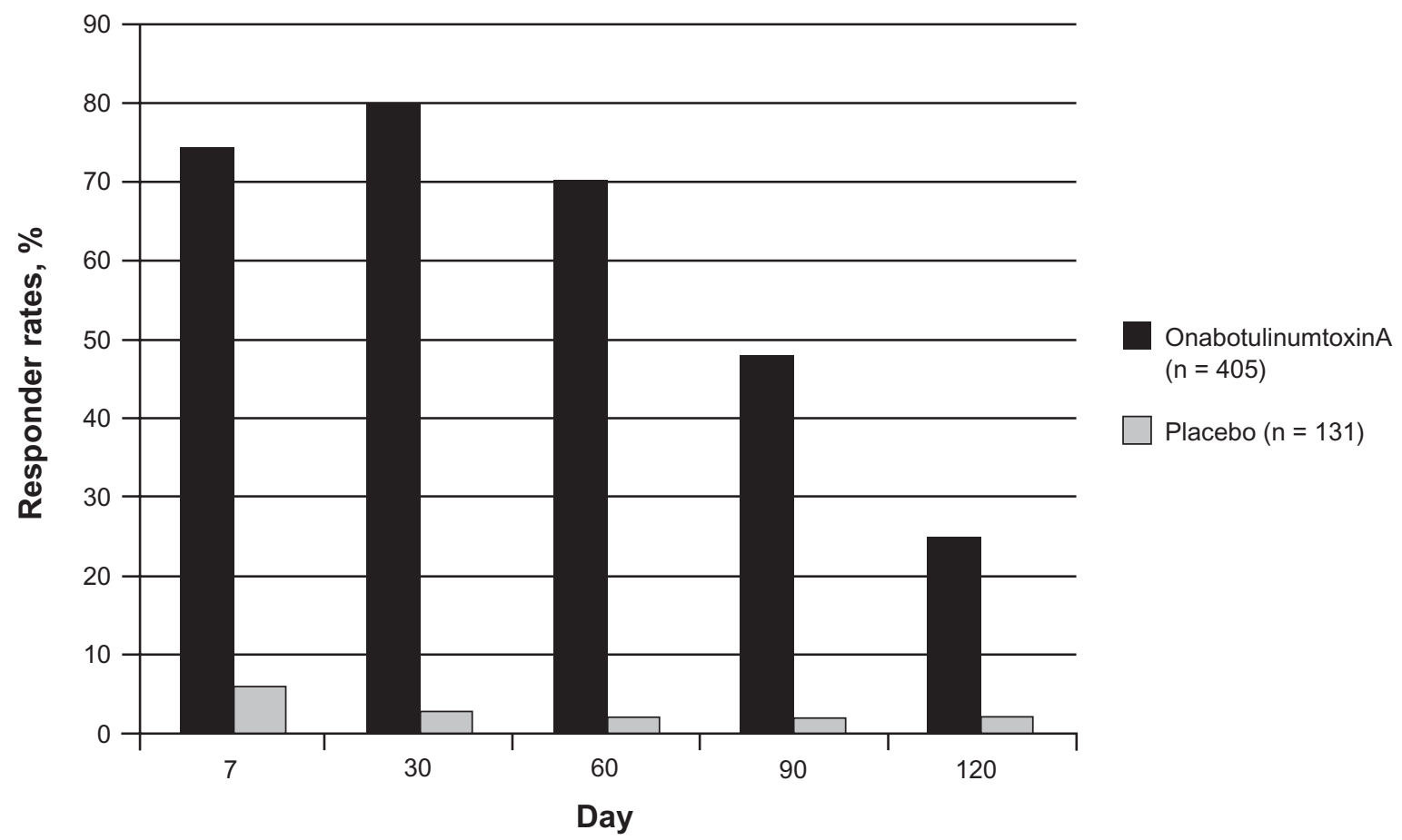

B

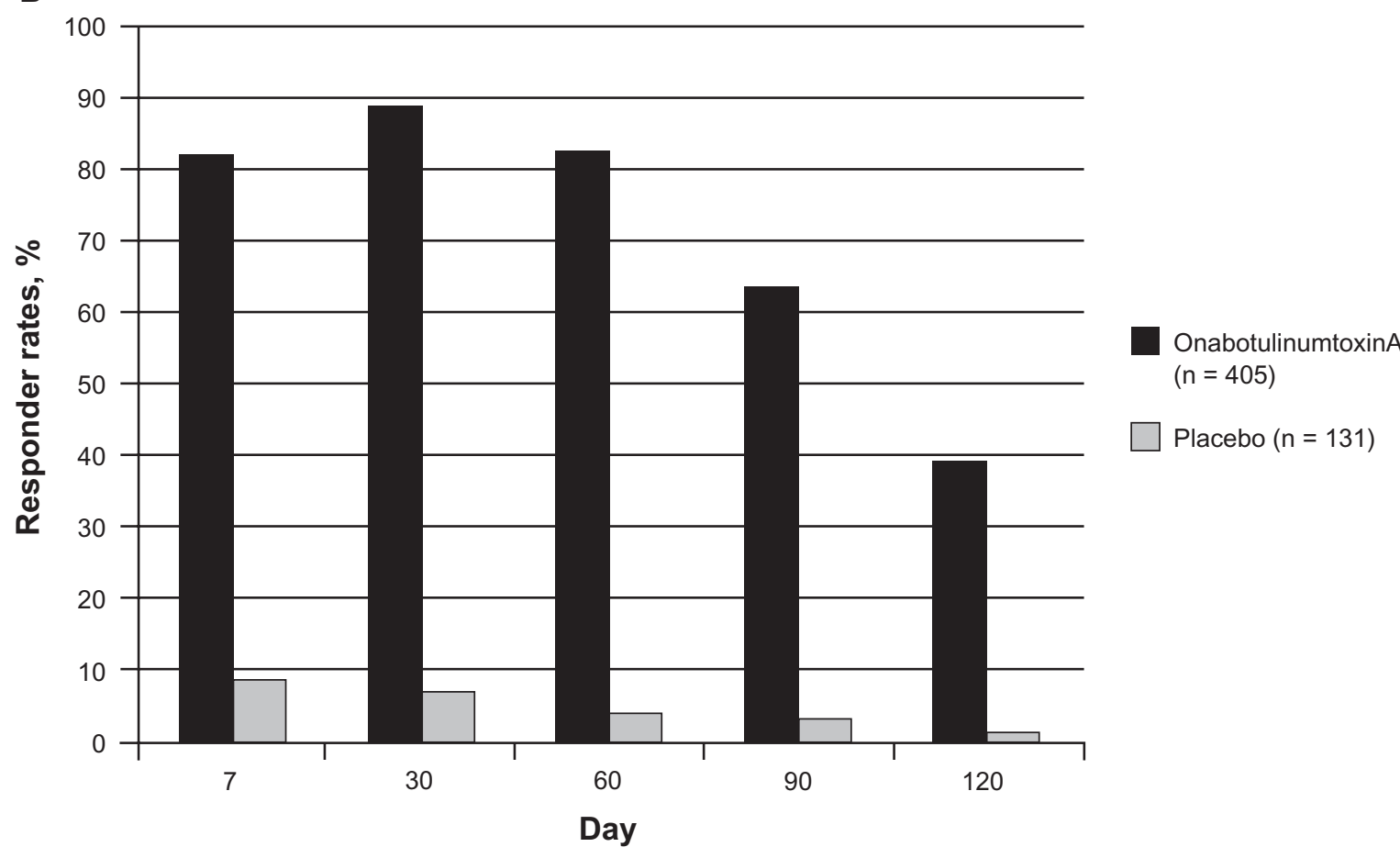

Figure I Responder rates at each follow-up visit after treatment with onabotulinumtoxinA during the double-blind period of the study. $\left.{ }^{45} \mathbf{A}\right)$ Physician's ratings of glabellar line severity at maximum frown. Responder rates were the percentage of subjects with ratings of none or mild. B) Subject's assessment of changes in the appearance of glabellar lines. Responder rates were the percentages of subjects with a least moderate improvement.

consistently less effective than the other doses. As is typical, peak responder rates occurred between weeks 2 and 4 , and ranged from $85 \%$ in the $10-\mathrm{U}$ group to $100 \%$ in the other treatment groups. The response rates with the higher doses did not differ significantly among each other. The duration of benefit was generally longer in the higher dosage groups.

Although response rate and response duration are associated with unit dose of onabotulinumtoxinA, dilution 


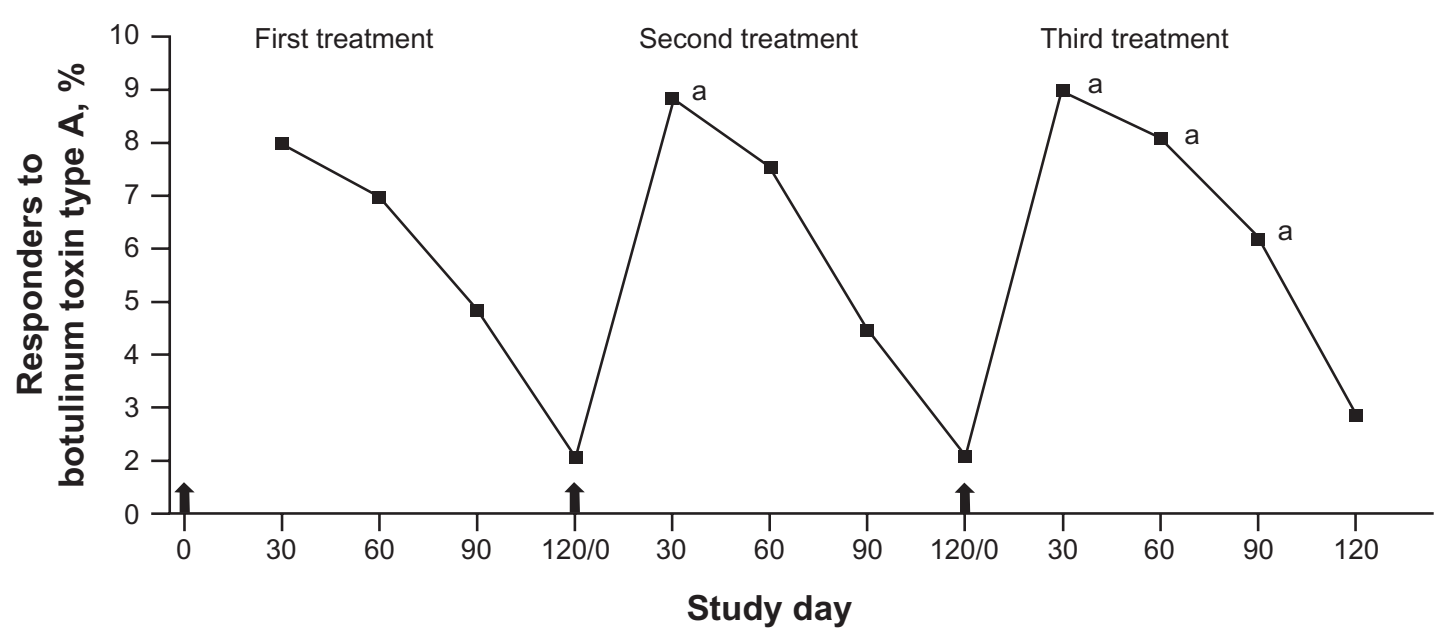

Figure 2 Responder rates (percentage of subjects with ratings of none or mild) following each of 3 treatments with onabotulinumtoxinA: based on physician's assessment of glabellar line severity at maximum frown $(n=258$; subjects receiving all 3 treatments).

Carruthers A, Carruthers J, Lowe NJ, et al; for the BOTOX ${ }^{\circledR}$ Glabellar Lines I and II Study Groups. One-year, randomised, multicenter, two-period study of the safety and efficacy of repeated treatments with botulinum toxin type A in patients with glabellar lines.J Clin Res. 2004;7: 1-20. ${ }^{41} @ 2004$ Informa Healthcare. Reproduced with permission.

andicates that the value is significantly greater than the value at the same time point after one or both previous botulinum toxin treatments $(P<0.028)$.

Arrow indicates time of botulinum toxin treatment.

does not appear to influence efficacy. In one study, a dose of $30 \mathrm{U}$ of onabotulinumtoxinA was delivered at 7 sites in the glabellar in varying dilutions. ${ }^{60}$ At the 4 dilutions used $(100,33.3,20$, or $10 \mathrm{U} / \mathrm{mL} ; \mathrm{N}=80,20$ /group), no differences in responder rates were observed among groups despite differences in the volumes injected per site. Responder rates peaked at week 2 and ranged from $95 \%$ to $100 \%$. The majority of patients had relapsed by week 24 , regardless of treatment group.
Two dosages, $20 \mathrm{U}(\mathrm{n}=15)$ and $30 \mathrm{U}(\mathrm{n}=16)$ of onabotulinumtoxinA were examined in a small, randomized, controlled study with African American women (skin types IV and IV). ${ }^{61}$ Subjects were evaluated at days 30, 60, 90, and 120 posttreatment. The peak response at day 30 was $92.4 \%$ for the $20-\mathrm{U}$ treatment group and $100 \%$ for the $30-\mathrm{U}$ group. No differences were observed between treatment groups, suggesting that clinicians can select the appropriate dose based on an individual's presentation. Although the vast majority of clinical

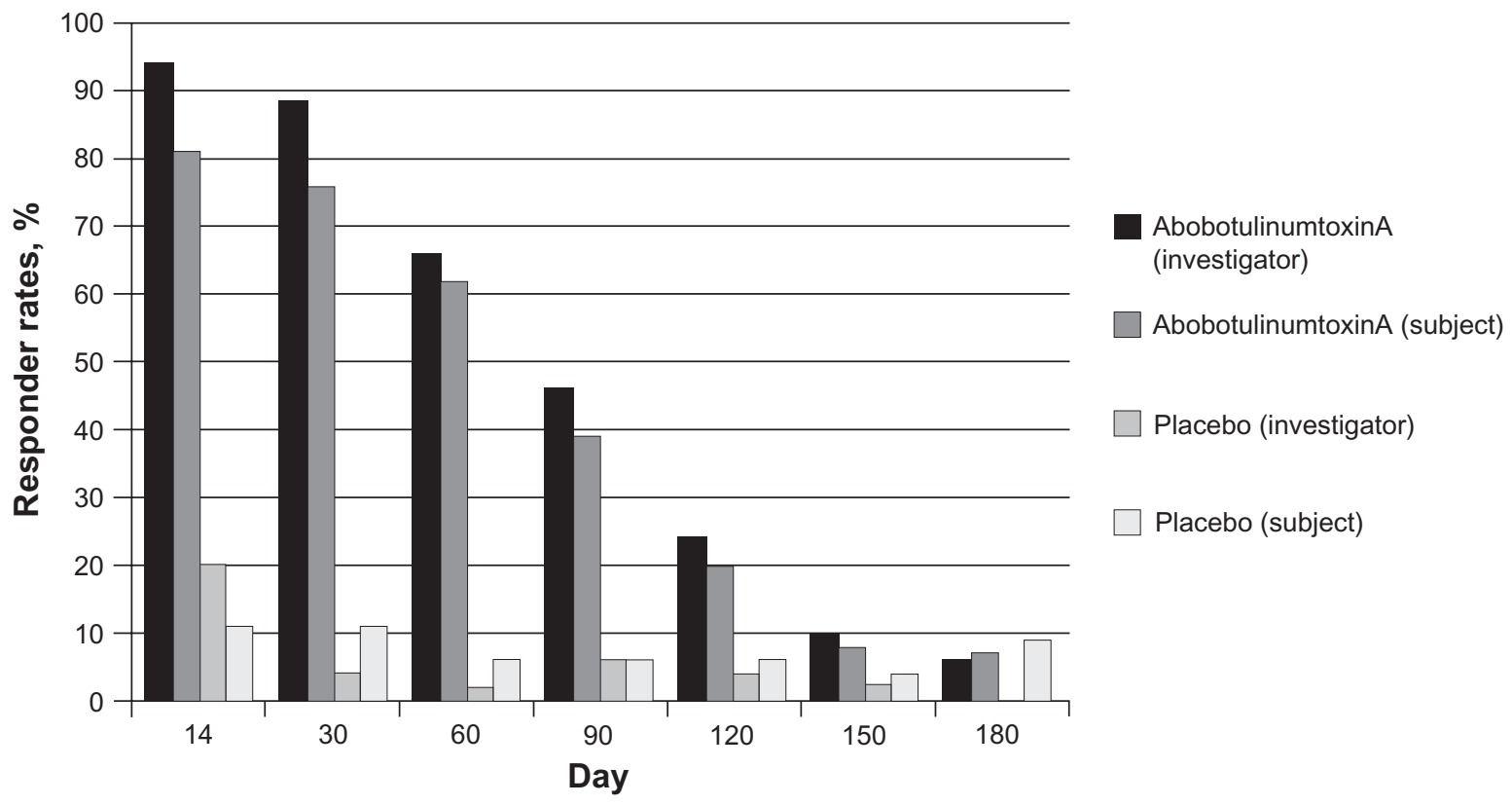

Figure 3 Percentage of subjects with glabellar severity of none or mild post treatment. ${ }^{56}$

Investigator and subject assessments - Study GL-I; abobotulinumtoxinA, $n=105$; placebo, $n=53$. 
studies have been conducted primarily with Caucasian females, the results from this study demonstrate that onabotulinumtoxinA is safe and effective for African American women.

\section{AbobotulinumtoxinA}

Three dosages $(25,50$, or $75 \mathrm{U})$ of abobotulinumtoxinA and placebo were studied in 119 patients. ${ }^{48}$ The $25-\mathrm{U}$ dose consistently resulted in lower responder rates than the other doses, although the percentage of responders differed from placebo through day 90 , but not at day 180 posttreatment. Data at 120 days were not provided. Responder rates at day 14 were $66 \%$ and $67 \%$ for the 50 - and $75-\mathrm{U}$ doses, respectively. Responder rates peaked at day 30 at $76 \%$ for the 2 higher doses. It appeared that the $75-\mathrm{U}$ dose provided somewhat higher response rates overall, but differences between dosage groups were not analyzed. Each group differed significantly from placebo through day 90 .

Another study with abobotulinumtoxinA compared 20, 50 , and $75 \mathrm{U}$ injected in 5 sites of the glabellar area. ${ }^{49}$ Follow-up in this study was through day 120. Although investigator-assessed responder rates were not reported for all time points, it was noted that the proportion of responders with the 20-U dose differed from placebo through day 90, whereas, the responder rates with the 50- and 75-U doses differed from placebo through day 120 posttreatment, at which time $26 \%$ and $27 \%$ respectively remained responders.

When 3 injections totaling $30 \mathrm{U}$ of abobotulinumtoxin $\mathrm{A}$ was compared with 5 injections ( $50 \mathrm{U}$ ) in a 16-week study of 221 subjects, responder rates at week 4 were approximately $86 \%$ for each treatment group ${ }^{62}$ and differed significantly from placebo. Responder rates for the duration of the study were not explicitly reported, but subject satisfaction ratings declined as would be expected over the course of the study. Nevertheless $60 \%$ to $70 \%$ of subjects remained at least moderately satisfied at week 16 . Efficacy was not affected by dose or number of injection sites in this study.

Based on standard clinical practice of adjusting dosing to muscle mass, investigators examined the results of varied dosing in male and female subjects $(50,60,70$, or $80 \mathrm{U}){ }^{63}$ The overall responder rate based on the blinded evaluator assessment at day 30 was $85 \%$. Some differences by subgroup were noted: for example, the younger the age, the greater the responder rate; the more severe the lines, the lower the responder rate. The responder rate for females $(87 \%)$ was higher than for males (65\%), and African American subjects had a slightly higher responder rate than Caucasians ( $89 \%$ vs $84 \%$, respectively). Statistical analyses were not, however, provided for these subgroup analyses.

\section{Comparative studies}

To our knowledge, only one double-blind, randomized, controlled study compared onabotulinumtoxinA (20 U) and abobotulinumtoxinA (50 U) for the treatment of glabellar lines. ${ }^{64}$ In this study, follow-up visits were conducted at weeks $2,8,12$, and 16 . The responder rate was defined as the proportion of subjects with an improvement from baseline of at least 1 grade in glabellar line severity on the 4-point scale. ${ }^{42}$ The peak response was observed at 8 weeks posttreatment with $94 \%$ of onabotulinumtoxinA-treated subjects and $97 \%$ of abobotulinumtoxinA-treated subjects meeting the response criterion. At week 16, a statistically significant different proportion of subjects in each group (onabotulinumtoxinA: 53\%; abobotulinumtoxinA: 28\%) continued to show this level of improvement. The incidence of subjects with glabellar severity of none or mild was $45 \%$ (onabotulinumtoxinA) and 50\% (abobotulinumtoxinA) at week 8 , and at no time point was the difference between treatment groups statistically significant.

In considering these results, it is important to note that mean age of subjects differed significantly by treatment group and that the proportions with moderate and severe glabellar lines at baseline were not identical, although that difference was not statistically significant. In addition, responder rates were not presented for the 2-week follow-up evaluation, and subjects were not assessed at 4 weeks posttreatment, the typical primary efficacy endpoint adopted in the larger scale clinical trials.

\section{Duration}

A comprehensive review on duration of effect for treating various facial areas has recently been published. ${ }^{28}$ It was concluded that patients can generally expect botulinum toxin type A treatment of their glabellar lines to last at least 3 months and sometimes longer. The specific impact of age, baseline glabellar rhytid severity, sex, number of previous treatments, and the impact of combination with other modalities remains to be clarified. In addition, for any estimates to be accurate, the study must have followed subjects for a long enough interval to capture those potential long-term responders.

Estimated duration depends considerably on how it is measured. For example, some studies with the onabotulinumtoxinA formulation measured time to relapse based on a return to baseline glabellar severity at 2 consecutive visits (30 days apart). ${ }^{58,59}$ In these studies, the mean time to relapse ranged from approximately 18 weeks (20-U dose) to 24 weeks ( $80-\mathrm{U}$ dose). ${ }^{58}$ The estimated mean duration in males was similar for doses ranging from 40 to $80 \mathrm{U} .^{58}$ 
In the one comparative study of onabotulinumtoxinA and abobotulinumtoxinA, the estimated relapse rates at week 16 were $23 \%$ and $40 \%$, respectively. ${ }^{64}$ This finding, however, was not statistically significant. Nevertheless, based on all the data in the study, the investigators concluded that onabotulinumtoxinA affords a longer duration of efficacy. ${ }^{64}$

Duration can also be based on the proportion of responders over time. This measure provides information about the longest potential duration that may occur in a limited number of patients (if the study duration is sufficient). When these data are presented in a study, mean or median response time can be derived.

In a study designed to determine duration based on when the next injection was scheduled, results indicated the majority of patients treated with abobotulinumtoxinA were reinjected between months 3 and $4 .{ }^{65}$ In clinical practice, versus trials, it is likely that those patients seeking retreatment will be influenced by a number of factors, such as appearance and cost. The impact of these factors will largely depend on the individual. For example, those who are most influenced by appearance may seek retreatment well before glabellar line severity has returned to baseline, whereas those for whom cost takes precedence are likely to wait somewhat longer before seeking retreatment. Based on available data, it appears that each product provides a range of duration, generally 3 to 5 months. In the absence of well-controlled comparative studies, it is not possible to determine how specific product properties interact with such other potential variables as baseline glabellar line severity, age, sex, ethnicity, and possibly injection techniques and patterns in duration.

In clinical practice, duration is also apt to be affected by numerous variables. As examples, patients may reschedule at the time of treatment and thus be retreated based on a fixed time, regardless of need; they may choose to be retreated before return to baseline to maintain a certain level of improvement in appearance. If they return to the office before return to baseline, dosing may be adjusted, which may affect subsequent response duration.

\section{Satisfaction with treatment and other PROs}

Patient satisfaction and other PROs comprise a number of outcome variables. Satisfaction with botulinum toxin treatment has been included in several major clinical trials and has been the subject of a recent comprehensive review. ${ }^{29}$ Most frequently, subjects rate their satisfaction on one of a number of categorical, Likert-type scales, such as the Facial Lines Treatment Satisfaction Questionnaire (FLTSQ), which ranges from "very dissatisfied" to "very satisfied". ${ }^{66,67}$ Across the studies reviewed, subject satisfaction ratings ranged from at least $60 \%$ to $100 \%$ following treatment for glabellar lines (Table 4). ${ }^{29,48,58,62,64,65,67-70}$

The comparative study between onabotulinumtoxinA and abobotulinumtoxinA suggested that subjects were more satisfied with onabotulinumtoxinA treatment, but significant differences were observed only at a single time point, week $16 .^{71}$ Another, open-label study found that patients treated with onabotulinumtoxinA and then switched to abobotulinumtoxinA rated their satisfaction to be higher with onabotulinumtoxinA treatment. ${ }^{72}$ Specifically, at a mean of 20 weeks posttreatment with onabotulinumtoxin A, 100\% of patients rated themselves as satisfied or extremely satisfied. In contrast, $31 \%$ of abobotulinumtoxinA-treatment patients rated themselves satisfied or extremely satisfied at a mean of 16 weeks posttreatment. The limitations of this study included the use of both retrospective and prospective data as well as the presence of other potentially confounding variables. One such confounding variable is the impact that cognitive dissonance may have had upon PROs and satisfaction. This phenomenon is recognized, but has not been studied with onabotulinumtoxinA. This may be an applicable area of research in facial aesthetics. ${ }^{73}$ Nevertheless, these findings suggest that additional controlled trials are warranted to help clinicians understand how patients perceive their responses to treatment with various available products to understand how best to use each product.

A prospective open-label study using the FLTSQ asked onabotulinumtoxinA-treated subjects to rate their satisfaction with the effects of treatment, with the experience of the procedure, and their overall treatment. ${ }^{67}$ At days 30 and 120 posttreatment, subject satisfaction was high; $95 \%$ of subjects were satisfied overall at day 30, and $86 \%$ remained satisfied at day $120 ; 88 \%$ and $82 \%$ were satisfied with the treatment effects at days 30 and 120, respectively, and 93\% and 95\% were satisfied with the experience at days 30 and 120 , respectively. Moreover, 88\% (day 30) and 82\% (day 120) of subjects reported satisfaction on individual items comprising the Effects of Treatment domain of the FLTSQ. These included aspects of appearance and feelings about appearance.

\section{Other PROs}

In addition to measuring satisfaction, investigators have recently begun to assess other outcomes deemed to be of importance to patients seeking aesthetic treatments. For example, the FLO questionnaire was developed to assess such specific outcomes as self-perception of age, perception of attractiveness, and the extent to which facial lines result in 
Table 4 Selected studies on subject satisfaction with botulinum toxin treatment ${ }^{\mathrm{a}}$

\begin{tabular}{|c|c|c|c|c|c|c|c|c|c|}
\hline First author & Treatment & $\begin{array}{l}\text { RCT } \\
(\mathbf{Y} / \mathbf{N})\end{array}$ & $\begin{array}{l}\text { No of } \\
\text { patients } \\
\text { (total) }\end{array}$ & Scale & $\begin{array}{l}\text { Selected } \\
\text { data }\end{array}$ & I month & 3 or 4 months & $\begin{array}{l}\text { Other time } \\
\text { points }\end{array}$ & $\begin{array}{l}\text { Assessment } \\
\text { time point } \\
\text { not specified }\end{array}$ \\
\hline \multicolumn{10}{|c|}{ OnabotulinumtoxinA glabellar studies } \\
\hline Stotland ${ }^{67}$ & $\begin{array}{l}\text { Onabotulinum- } \\
\text { toxinA }\end{array}$ & $\mathrm{N}$ & 58 & $\begin{array}{l}\text { Satisfaction } \\
\text { (14 items, } \\
7 \text { points; } \\
\text { FLTSQ) }\end{array}$ & $\begin{array}{l}\text { Percentage } \\
\text { somewhat } \\
\text { satisfied, } \\
\text { satisfied, } \\
\text { or very } \\
\text { satisfied }\end{array}$ & $\begin{array}{l}20 \text { U: } 95 \% \\
\text { (Overall), } 88 \% \\
\text { (treatment } \\
\text { effects), 95\% } \\
\text { (procedure) }\end{array}$ & $\begin{array}{l}20 \text { U: } 86 \% \\
\text { (Overall), } \\
8 \text { (treatment } \\
\text { effects), } \\
93 \% \\
\text { (procedure) }\end{array}$ & & \\
\hline Beer 68 & $\begin{array}{l}\text { Onabotulinum- } \\
\text { toxinA }\end{array}$ & $\mathrm{Y}$ & 77 & $\begin{array}{l}\text { Satisfaction } \\
\text { ( } 5 \text { categories) }\end{array}$ & $\begin{array}{l}\text { Percentage } \\
\text { satisfied } \\
\text { or very } \\
\text { satisfied }\end{array}$ & 20 U: $71.4 \%$ & 20 U: $83.4 \%$ & & \\
\hline Carruthers $^{58}$ & $\begin{array}{l}\text { Onabotulinum- } \\
\text { toxinA }\end{array}$ & Y & 80 & $\begin{array}{l}\text { Satisfaction } \\
\text { (not } \\
\text { stated) }\end{array}$ & $\begin{array}{l}\text { Percentage } \\
\text { satisfied } \\
\text { or very } \\
\text { satisfied }\end{array}$ & & & & $\begin{array}{l}20 \text { U: } 66 \% \\
30 \text { U: } 70 \% \\
40 \text { U: } 79 \%\end{array}$ \\
\hline Grimes $^{69}$ & $\begin{array}{l}\text { Onabotulinum- } \\
\text { toxinA }\end{array}$ & Y & 31 & $\begin{array}{l}\text { Satisfaction } \\
\text { (5 points) }\end{array}$ & $\begin{array}{l}\text { Percentage } \\
\text { satisfied } \\
\text { or very } \\
\text { satisfied }\end{array}$ & $\begin{array}{l}20 \mathrm{U} / 30 \mathrm{U:} \\
100 \%\end{array}$ & 20 U/30 U: $60 \%$ & & \\
\hline Ellis $^{70}$ & $\begin{array}{l}\text { Onabotulinum- } \\
\text { toxinA }\end{array}$ & $\mathrm{N}$ & 15 & $\begin{array}{l}\text { Satisfaction } \\
\text { (5 points) }\end{array}$ & $\begin{array}{l}\text { Mean score; } \\
5 \text { is most } \\
\text { satisfactory }\end{array}$ & & & $\begin{array}{l}4 \text { (7-10 days); } \\
\text { individualized } \\
\text { dosing }\end{array}$ & \\
\hline \multicolumn{10}{|c|}{ AbobotulinumtoxinA glabellar studies } \\
\hline Ascher 65 & $\begin{array}{l}\text { Abobotulinum- } \\
\text { toxinA }\end{array}$ & Y & 100 & $\begin{array}{l}\text { Satisfaction } \\
\text { (4 points) }\end{array}$ & $\begin{array}{l}\text { Percentage } \\
\text { satisfied } \\
\text { or very } \\
\text { satisfied }\end{array}$ & 50 U: $78 \%$ & $\begin{array}{l}3 \text { months: } 73.5 \% \\
4 \text { months: } 75.0 \%\end{array}$ & & \\
\hline Rzany ${ }^{62}$ & $\begin{array}{l}\text { Abobotulinum- } \\
\text { toxinA }\end{array}$ & Y & 221 & $\begin{array}{l}\text { Satisfaction } \\
\text { (4 points) }\end{array}$ & $\begin{array}{l}\text { Percentage } \\
\text { satisfied } \\
\text { or very } \\
\text { satisfied }\end{array}$ & & $\begin{array}{l}30 \text { U: } 32.3 \% \\
50 \text { U: } 43.9 \%\end{array}$ & & \\
\hline Ascher ${ }^{48}$ & $\begin{array}{l}\text { Abobotulinum- } \\
\text { toxinA }\end{array}$ & Y & 119 & $\begin{array}{l}\text { Satisfaction } \\
\text { (4 points) }\end{array}$ & $\begin{array}{l}\text { Percentage } \\
\text { satisfied } \\
\text { or very } \\
\text { satisfied }\end{array}$ & $\begin{array}{l}25 \text { U: } 65.5 \% \\
50 \text { U: } 86.2 \% \\
75 \text { U: } 75.8 \%\end{array}$ & $\begin{array}{l}25 \text { U: } 82.1 \% \\
50 \text { U: } 72.4 \% \\
75 \text { U: } 72.4 \%\end{array}$ & $\begin{array}{l}6 \text { months; } \\
25 \text { U: } 68.9 \% \\
50 \text { U: } 93.1 \% \\
75 \text { U: } 62.0 \%\end{array}$ & \\
\hline \multicolumn{10}{|c|}{ Comparative glabellar study } \\
\hline Lowe $^{64}$ & $\begin{array}{l}\text { Onabotulinum- } \\
\text { toxinA vs } \\
\text { abobotulinum- } \\
\text { toxinA }\end{array}$ & Y & 30 & $\begin{array}{l}\text { Satisfaction } \\
\text { (7 points) }\end{array}$ & $\begin{array}{l}\text { Mean score; } \\
7 \text { was most } \\
\text { satisfactory }\end{array}$ & & $\begin{array}{l}20 \mathrm{U}: \text { Onabotulinum- } \\
\text { toxinA: } 3.8 \\
50 \mathrm{U} \text { : Abobotulinum- } \\
\text { toxinA: } 2.7\end{array}$ & & \\
\hline
\end{tabular}

aPlacebo or comparative agent data are not presented for the purposes of this table. Botulinum toxin type A treatments consistently differed statistically from placebo or comparative agents.

Please refer to individual studies.

Adapted with permission from Fagien S, Carruthers JDA. A comprehensive review of patient-reported satisfaction with botulinum toxin type A for aesthetic procedures. Plast Reconstr Surg. 2008; I22(6): 1915-1925. ${ }^{29}$ Copyright (C) 2008Wolters Kluwer Health.

Abbreviations: RCT, randomized controlled trial; FLTSQ, Facial Lines Treatment Satisfaction Questionnaire.

looking tired, stressed, or angry when that does not coincide with the way the patient feels. ${ }^{74,75}$ The FLO questionnaire has been used to assess the effect of onabotulinumtoxinA treatment on multiple upper facial line areas, as well as moderate to severe glabellar lines alone. . $5,76^{-1}$
The glabellar-specific FLO questionnaire (7 items, FLO-7) was used to evaluate PROs in subjects with moderate to severe glabellar lines. ${ }^{76}$ The study included a Self-Perception of Age (SPA) item. Subjects randomly assigned to receive either onabotulinumtoxin $A(n=35)$ or placebo $(n=35)$ were 
evaluated at 4 weeks posttreatment for the double-blind phase of the study. At that time, subjects whose glabellar lines remained moderate to severe were offered open-label treatment with onabotulinumtoxinA.

At the 4-week evaluation, subjects treated with onabotulinumtoxinA for mild to moderate glabellar lines reported looking a mean of 4 years younger than at baseline. Placebo-treated subjects reported no changes, and the differences between groups was statistically significant. ${ }^{76}$ Statistically significant changes $(P=0.01)$ in self-perceptions of age were maintained through the 12 weeks of the study in the subjects initially treated with onabotulinumtoxinA. Similarly, onabotulinumtoxinA-treated subjects exhibited significant improvements on the FLO-7 at 4 weeks posttreatment (Figure 4). ${ }^{76}$ Responder rates in this study were consistent with those of other major clinical trials: $85 \%$ of subjects were deemed responders by investigators at week $4,86 \%$ at week 8 , and $67 \%$ at week 12 . The results of these studies demonstrate that onabotulinumtoxinA treatment provides efficacy as traditionally assessed by so-called objective measures in randomized controlled trials (ie, wrinkle severity on a 4-point scale), but also as evaluated by endpoints that are likely to be most important to how patients look and feel about themselves.

\section{PROs and treatment continuation}

Adherence refers to patients' persistence with a therapeutic regimen. In aesthetic medicine, this concept is reflected in the choices our patients make about continuing with a treatment plan and in their selection of specific products and procedures. It is important to understand the factors and considerations that contribute to our patients' willingness to return for treatment and even their readiness to recommend treatment to their friends. It can be hypothesized that adherence to a treatment regimen would be strongly influenced by our patients' satisfaction with their outcomes.

One of the earlier studies that evaluated patient satisfaction, included attitudes on beauty and body, treatment outcome satisfactions, and general quality of life. ${ }^{77}$ Thirty patients who had received onabotulinumtoxinA treatment for upper facial lines (primarily glabellar) within the previous 3 months were surveyed on patients attitudes on beauty and body using scales of the Freiburg Questionnaire on Aesthetic Dermatology and Cosmetic Surgery (FQAD) and the Freiburg Life Quality Assessment core (FLQA-C) version. More than $80 \%$ reported that treatment with onabotulinumtoxinA was beneficial, and $100 \%$ of the patients would recommend it (Figure 5). ${ }^{77}$ Patients also reported feeling more attractive and more comfortable with their bodies (Table 5). ${ }^{77}$

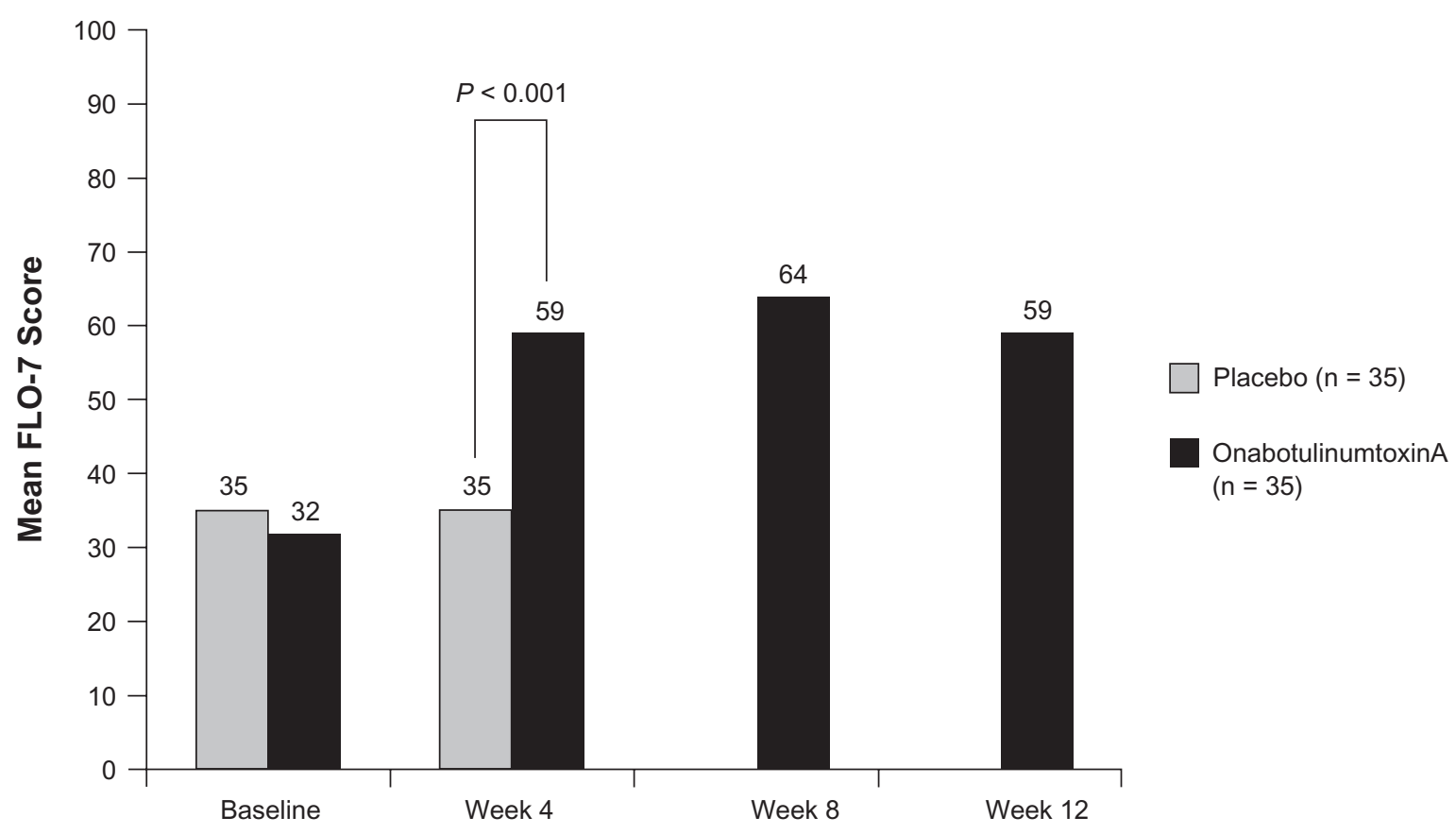

Figure 4 Mean FLO scores after onabotulinumtoxinA or placebo treatment in subjects with moderate to severe glabellar lines. The double-blind phase of the study was 4 weeks in duration, but subjects were followed for 12 weeks.

Reprinted with permission from Fagien S, Cox SE, Finn JC, Werschler WP, Kowalski JW. Patient-reported outcomes with botulinum toxin type A treatment of glabellar rhytids: a double-blind, randomized, placebo-controlled study. Dermatol Surg. 2007;33(I Spec No):S2-S9.76 @ John Wiley \& Sons Inc; 2007.

Abbreviation: FLD, Facial Lines Outcomes Questionnaire. 
The probability that a patient will continue with a treatment plan is likely to be based on other factors in addition to their reported satisfaction. Optimal outcomes are ultimately the result of an interaction of patients, physician, and practice attributes.

\section{Ensuring optimal outcomes}

A clinician's responsibility is to understand each patient's unique needs, goals, and expectations, and to establish realistic expectations. This has been duly stressed in many published studies and consensus recommendations. ${ }^{78,79}$ Certainly, all clinicians have encountered potential patients who are not acceptable candidates for specific aesthetic procedures, whether because of medical or psychological factors. As the field of aesthetic medicine has continued to evolve, knowledge about ways to increase the likelihood of optimal outcomes in appropriate candidates has continued to progress.

\section{Achieving a harmonious, balanced look}

For example, the principles of facial rejuvenation have come to embrace a more natural, relaxed look. ${ }^{79}$ One consequence is the use of lower doses of onabotulinumtoxinA to treat certain facial areas such as the forehead. ${ }^{79}$ Another is the recognition that facial areas ought not to be treated
Table 5 Patient satisfaction with onabotulinumtoxinA treatment as assessed by items on the FQAD $(\mathrm{N}=30)$

\begin{tabular}{ll}
\hline Answer & OnabotulinumtoxinA, \% \\
\hline I recommend the treatment & 100.0 \\
The treatment was beneficial to me & 80.0 \\
I was stressed by treatment & 0.0 \\
I feel more attractive & 55.1 \\
I feel more comfortable with my body & 76.7 \\
My emotional well-being is better & 30.0 \\
I have more confidence in my appearance & 44.8 \\
I can profit from the treatment in my job & 20.6 \\
I don't like to tell others about & 13.3 \\
the treatment &
\end{tabular}

Reprinted with permission from Sommer B, Zschocke I, Bergfeld D, Sattler G, Augustin M. Satisfaction of patients after treatment with botulinum toxin for dynamic facial lines. Dermatol Surg. 2003;29(5):456-460..7 @ John Wiley \& Sons Inc, 2003.

in isolation, but as a part of an overall aesthetic treatment plan. One placebo-controlled study $(\mathrm{N}=40)$ demonstrated that treating multiple upper facial lines (glabellar, forehead, crow's feet) with onabotulinumtoxinA (64 $\mathrm{U}$ in 16 sites;) was both effective and well tolerated. ${ }^{75}$ Responder rates at week 4 for each facial area were $100 \%$ at both repose and maximal contraction, with the exception of the crow's feet at maximal

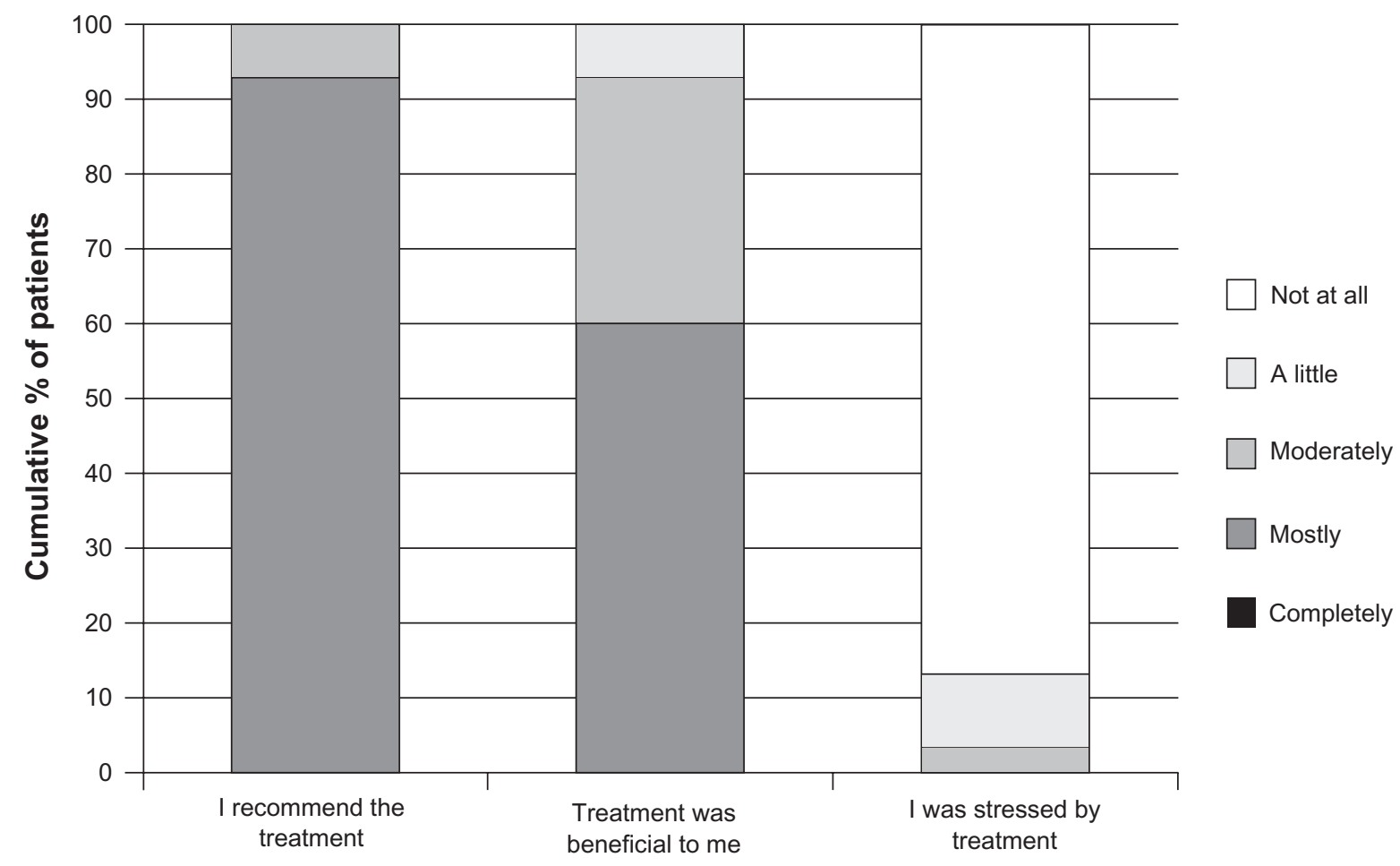

Figure 5 Patients' reactions to treatment with onabotulinumtoxinA $(N=30)$.

Reprinted with permission from Sommer B, Zschocke I, Bergfeld D, Sattler G, Augustin M. Satisfaction of patients after treatment with botulinum toxin for dynamic facial lines. Dermatol Surg. 2003;29(5):456-460. ${ }^{77}$ C John Wiley \& Sons Inc, 2003. 
contraction ( $85 \%$ ). In addition, scores on the FLO-7 improved significantly at week 4 and were maintained throughout the 12-week trial. AEs were mild and transient, and ptosis did not occur in this study. Probable treatment-related AEs during the double-blind phase included one instance of tightness across the forehead and one instance of pulling lines at the outer eyelid ( 20 subjects total). ${ }^{75}$

Treating multiple upper facial lines, in contrast to the glabellar alone, may result in a greater magnitude of improvement. ${ }^{75,76}$ Although a direct comparison has not been undertaken in a trial, it is interesting to consider the results of the 2 studies that used the FLO questionnaire to evaluate PROs. ${ }^{75,76}$ With the exception of the number of sites injected and the total number of onabotulinumtoxinA units per subject, the study protocols were identical. Figure 6 illustrates the improvement in FLO scores at week 4 from each study. ${ }^{75,76}$ Note that baseline scores on the FLO were identical within and between studies. Treating multiple facial areas coincides with much of current clinical practice.

\section{Combining modalities}

Another approach to optimizing outcomes is the use of minimally invasive modalities in combination. Botulinum toxin has long been considered the foundation of treatments for the upper face, whereas fillers are the preferred method of treating the lower face. ${ }^{79}$ As techniques and products have evolved, it has become clear that combinations afford excellent and safe results, while addressing the multidimensional characteristics of facial aging. This approach was addressed in detail in a recent consensus publication on the use of botulinum toxins and hyaluronic acids. ${ }^{79}$

In subjects with severe glabellar rhytids, subjects who received onabotulinumtoxinA (30 U) as well as nonanimal, stabilized, hyaluronic acid (NASHA) experienced a substantially prolonged outcome. ${ }^{80}$ Specifically the median time to baseline furrow severity was 18 weeks in the group treated with NASHA compared with 32 weeks for the group receiving onabotulinumtoxinA plus NASHA. Combination treatment did not increase the incidence of AEs.

Other studies have demonstrated the safety and efficacy of onabotulinumtoxinA in combination with any of a number of modalities including collagen, intense pulsed light, and laser resurfacing. ${ }^{81-86}$ Consistently, combination therapy provides subjects with additional benefits versus monotherapy. The effects of abobotulinumtoxinA in combination with other aesthetic modalities remain to be evaluated.

Another aspect of achieving optimal outcomes is to tailor treatment to each individual. Typically, clinical trials of botulinum toxins utilize fixed dosing regimens. A recent study with abobotulinumtoxinA allowed variable dosing within the range of 50 to $70 \mathrm{U}$ in females and 40 to $80 \mathrm{U}$ in males, depending on investigator-assessed mass of the corrugators and procerus muscles. ${ }^{63}$ Doses of abobotulinumtoxinA were well tolerated and resulted in responder rates typical of fixed dose studies. The results confirmed the utility of adjusting dosing to clinical presentation, which is typical of clinical practice. The design of the study, however, did not include assessment of PROs, including satisfaction, nor was standardized dosing compared directly with variable dosing based on muscle mass and gender. Nevertheless, the results indicate that doses can be increased as needed without sacrificing tolerability. The dose-ranging studies conducted with onabotulinumtoxin A in males and females also demonstrated that increasing the dose within the ranges studied did not increase the incidence of AEs. ${ }^{58,59}$

\section{Avoiding complications}

Beyond an in-depth understanding of facial anatomy and physiology, clinicians must thoroughly understand the properties of each product they use in their practices because, as discussed, each is unique. Specific potential complications and how to avoid them have been reviewed extensively, particularly for the onabotulinumtoxinA formulation because of its longer history of research and use..$^{78,79,87,88}$ The vast majority of complications are mild and transient.$^{87}$ More serious or unwanted effects such as ptosis can often be traced to lack of experience or poor technique and subsequent diffusion to adjacent musculature from the site of injections. Because formulations may differ in their diffusion characteristics, a subject of some lively discussion, it is essential that clinicians become completely familiar with the performance of any specific product in their own hands..$^{37,39}$

\section{Summary and conclusions}

The advent of botulinum toxin use for the treatment of glabellar lines heralded a new era in aesthetic medicine and an unparalleled growth in the annual number of procedures over the decade from 1997 to $2007 .{ }^{89,90}$ In the United States alone, nearly 2.5 million botulinum toxin procedures were performed in 2008 and were attributed to the onabotulinumtoxinA formulation. ${ }^{89}$ The approval of another botulinum type A formulation, abobotulinumtoxinA, may be expected to spur competition and additional usage. With FDA approval of this formulation for the treatment of glabellar lines has come a new warning, generated primarily by concerns for safety in therapeutic, in contrast to cosmetic, 
A

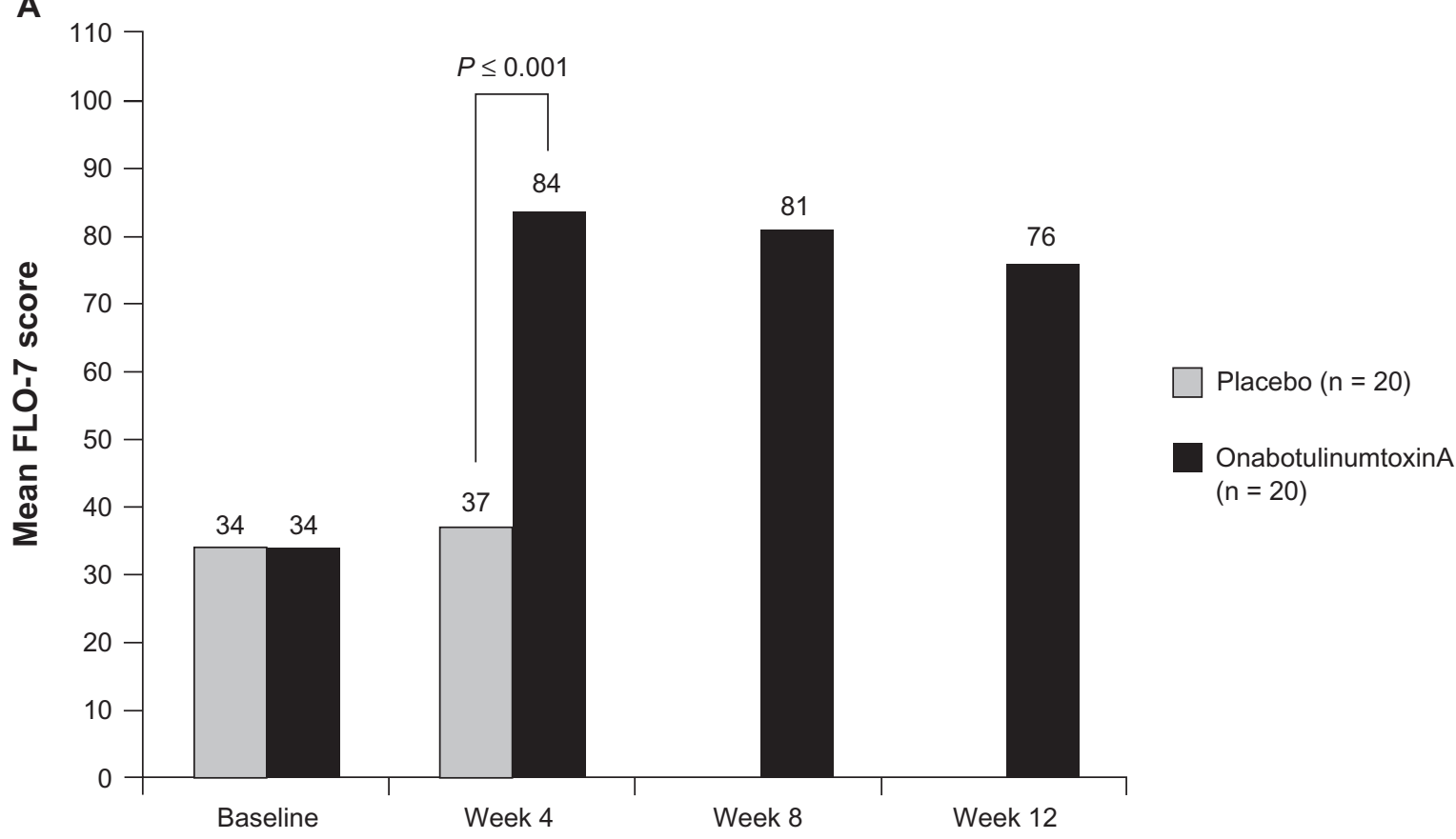

B

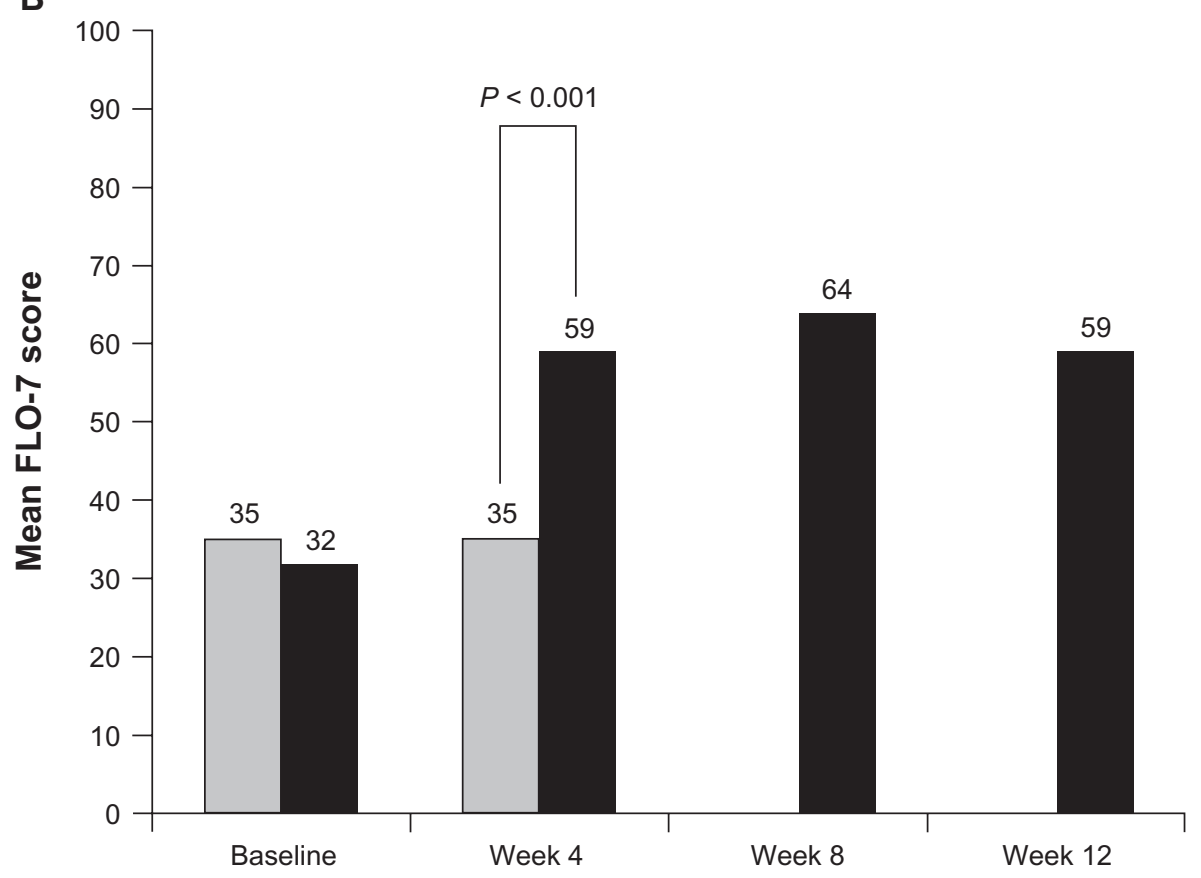

Placebo $(n=35)$

OnabotulinumtoxinA $(n=35)$

Figure 6 Improvements in FLO scores in 2 studies following treatment with onabotulinumtoxinA.

A) Reprinted with permission from Carruthers J, Carruthers A. Botulinum toxin type A treatment of multiple upper facial sites: patient-reported outcomes. Dermatol Surg. 2007;33(I Spec No):SI0-SI7.75 @ John Wiley \& Sons Inc; 2007. B) Reprinted with permission from Fagien S, Cox SE, Finn JC, Werschler WP, Kowalski JW. Patient-reported outcomes with botulinum toxin type A treatment of glabellar rhytids: a double-blind, randomized, placebo-controlled study. Dermatol Surg. 2007;33(I Spec No):S2-S9.76 @ John Wiley \& Sons Inc; 2007.

indications. Nevertheless, this is an important reminder that all medical procedures and products carry unique benefit:risk profiles. Not only must clinicians be thoroughly familiar with these, they must be able to educate their patients as well as establish realistic expectations.
One of the important changes that has come about with the new product labeling for botulinum toxins approved for use in the United States is the adoption of new established (nonproprietary) names. The name changes underscore that even with a given serotype, such as botulinum toxin type A, 
formulations are not interchangeable. This labeling change should not surprise experienced clinicians, who may have observed differences in the clinical performance of available products. The recognition that biologic agents derived from similar sources are not necessarily biosimilar is also consistent with findings on other aesthetic products, such as hyaluronic acid fillers, as well as with other therapeutic categories. This means that clinicians cannot apply techniques and dosing from one formulation to another, but must rather learn how to use each product properly to provide optimal and safe outcomes for their patients. As in other medical settings, clinicians perform a thorough pretreatment assessment followed by the development of a comprehensive, individualized treatment plan that includes the most appropriate products and procedures, ongoing assessment, and modification of the plan as needed. Because of the lack of head-to-head studies between available products, much research is still required to provide more information on how formulations perform with respect to all outcomes, including satisfaction and other important patient-reported endpoints.

As more about the bidirectional effects of facial expression is learned - influencing mood, psychological state, self-perception, and perception by others, it is anticipated that botulinum toxin type A will continue to play a pivotal role in facial aesthetics and rejuvenation, whether used alone or in combination with other modalities. Although botulinum toxin type A remains the cornerstone of upper facial treatment, clinicians in aesthetic medicine have come to understand that patients deserve a full facial aesthetic evaluation with the treatments selected based on their individual goals and desires. Within this context, additional information to help patients make informed decisions on choice of products and procedures can be offered.

\section{Acknowledgments}

Editorial support was provided by Paula G. Davis, $\mathrm{PhD}$, and Greg Tardie, PhD, of Health Learning Systems, Parsippany, NJ, USA. Funding for editorial support was provided by Allergan, Inc., Irvine, USA.

\section{Disclosures}

Dr De Boulle is a consultant and speaker for Allergan, Inc.

Dr Fagien is a consultant for Allergan, Inc. and Bioform Medical, Inc. Dr Fagien is a clinical investigator for Allergan, Inc., Medicis, Mentor, and Dermik/Sanofi-Aventis.

Dr Glogau is a consultant and clinical investigator for Allergan, Inc.

Dr Sommer is a consultant for Allergan, Inc., Revance, Medicis, Fibrogen, Contura, Fziomed, Liposonix, and Neutrogena. Dr Sommer is a clinical investigator for Allergan, Inc.

\section{References}

1. Shakespeare W. The Tragedy of Macbeth. Act 1, scene 4, line 13.

2. Lewis MB, Bowler PJ. Botulinum toxin cosmetic therapy correlates with a more positive mood. J Cosmet Dermatol. 2009;8(1):24-26.

3. Ekman P. Facial expression and emotion. Am Psychol. 1993;48(4): 384-392.

4. Heckmann M, Teichmann B, Schroder U, Sprengelmeyer R, Ceballos-Baumann AO. Pharmacologic denervation of frown muscles enhances baseline expression of happiness and decreases baseline expression of anger, sadness, and fear. J Am Acad Dermatol. 2003;49(2):213-216.

5. Strack F, Neumann R. Furrowing the brow may undermine perceived fame: the role of facial feedback in judgments of celebrity. Pers Soc Psychol Bull. 2000;26(7):762-768.

6. Dimberg U. Facial reactions to fear-relevant and fear-irrelevant stimuli. Biol Psychol. 1986;23(2):153-161.

7. Hoffmann K, Hahn C, Leising D, Bechara FG, Georgas D, Tomi NS. "Emotional expressivity" after botulinumtoxin anti-wrinkle treatment. [poster] 21st Annual World Congress of Dermatology. September 30October 5, 2007; Buenos Aires, Argentina.

8. Hoffmann K, Hahn C, Leising D, Bechara FG, Georgas D, Tomi NS. "Interpersonal attraction" and "well-being" after botulinumtoxin antiwrinkle treatment. [poster] 21st Annual World Congress of Dermatology. September 30-October 5, 2007; Buenos Aires, Argentina.

9. Mac Pherson S. Self-esteem and cosmetic enhancement. Plast Surg Nurs. 2005;25(1):5-20.

10. Strack F, Martin LL, Stepper S. Inhibiting and facilitating conditions of the human smile: a nonobtrusive test of the facial feedback hypothesis. J Pers Soc Psychol. 1988;54(5):768-777.

11. VanSwearingen JM, Cohn JF, Bajaj-Luthra A. Specific impairment of smiling increases the severity of depressive symptoms in patients with facial neuromuscular disorders. Aesthetic Plast Surg. 1999;23(6): 416-423.

12. Finzi E, Wasserman E. Treatment of depression with botulinum toxin A: a case series. Dermatol Surg. 2006;32(5):645-649.

13. Leffell DJ. Foreword. In: Kaminer MS, Dover JS, Arndt KA, editors. Atlas of Cosmetic Surgery. 1st ed. Philadelphia, Pa: W. B. Saunders Company; 2001. p. ix-x.

14. Carruthers JDA, Carruthers JA. Treatment of glabellar frown lines with C. botulinum-A exotoxin. J Dermatol Surg Oncol. 1992;18(1):17-21.

15. Allergan Inc. Botox Cosmetic: About Safety. http://www.botoxcosmetic. com/botox_safety/fda_approval.aspx. Accessed September 1, 2009.

16. US Food and Drug Administration. FDA Requires Boxed Warning for All Botulinum Toxin Products. http://www.fda.gov/NewsEvents/ Newsroom/PressAnnouncements/ucm 149574.htm. Accessed August 25, 2009.

17. Flynn TC, Clark RE. Botulinum toxin type B (Myobloc) versus botulinum toxin type A (Botox) frontalis study: rate of onset and radius of diffusion. Dermatol Surg. 2003;29(5):519-522.

18. Baumann L, Slezinger A, Vujevich J, et al. A double-blinded, randomized, placebo-controlled pilot study of the safety and efficacy of Myobloc (botulinum toxin type B)-purified neurotoxin complex for the treatment of crow's feet: a double-blinded, placebo-controlled trial. Dermatol Surg. 2003;29(5):508-515.

19. Glogau RG. Topically applied botulinum toxin type a for the treatment of primary axillary hyperhidrosis: results of a randomized, blinded, vehiclecontrolled study. Dermatol Surg. 2007;33(1 Spec No):S76-S80.

20. Aoki KR, Guyer B. Botulinum toxin type A and other botulinum toxin serotypes: a comparative review of biochemical and pharmacological actions. Eur J Neurol. 2001;8(Supp1 5):21-29.

21. Aoki KR. Botulinum toxin: a successful therapeutic protein. Curr Med Chem. 2004;11(23):3085-3092.

22. Carruthers A, Carruthers J. Botulinum toxin products overview. Skin Therapy Lett. 2008;13(6):1-4.

23. Baumann L, Black L. Botulinum toxin type B (Myobloc). Dermatol Surg. 2003;29(5):496-500. 
24. Sadick NS. Prospective open-label study of botulinum toxin type B (Myobloc) at doses of 2,400 and 3,000 $\mathrm{U}$ for the treatment of glabellar wrinkles. Dermatol Surg. 2003;29(5):501-507.

25. Ramirez AL, Reeck J, Maas CS. Botulinum toxin type B (MyoBloc) in the management of hyperkinetic facial lines. Otolaryngol Head Neck Surg. 2002;126(5):459-467.

26. Klein AW, Carruthers A, Fagien S, Lowe NJ. Comparisons among botulinum toxins: an evidence-based review. Plast Reconstr Surg. 2008;121(6):413e-422e.

27. Aoki KR. Pharmacology and immunology of botulinum neurotoxins. Int Ophthalmol Clin. 2005;45(3):25-37.

28. Flynn TC. Botulinum toxin: examining duration of effect in facial aesthetic. Am J Clin Dermatol. In press 2009.

29. Fagien S, Carruthers JDA. A comprehensive review of patient-reported satisfaction with botulinum toxin type A for aesthetic procedures. Plast Reconstr Surg. 2008;122(6):1915-1925.

30. De Boulle KLV. Botulinum neurotoxin type A in facial aesthetics. Expert Opin Pharmacother. 2007;8(8):1059-1072.

31. Dolly JO, Aoki KR. The structure and mode of action of different botulinum toxins. Eur J Neurol. 2006;13(Suppl 4):1-9.

32. Frevert J. Xeomin is free from complexing proteins. Toxicon. 2009; $1-5$.

33. Hunt T, Clarke K. Potency evaluation of a formulated drug product containing 150-kd botulinum neurotoxin type A. Clin Neuropharmacol. 2009;32(1):28-31.

34. Jost WH, Kohl A, Brinkmann S, Comes G. Efficacy and tolerability of a botulinum toxin type A free of complexing proteins (NT 201) compared with commercially available botulinum toxin type A (BOTOX) in healthy volunteers. J Neural Transm. 2005;112(7):905-913.

35. Rosales RL, Bigalke H, Dressler D. Pharmacology of botulinum toxin: differences between type A preparations. Eur J Neurol. 2006; 13(Suppl 1):2-10.

36. Aoki KR, Satorius A, Ardila C, Brown M, Nicholson G, Francis J. Pharmacology of BOTOX, Dysport, Myobloc and BTX-A in animal models of efficacy and safety. [abstract] International Conference on Basic and Therapeutic Aspects of Botulinum and Tetanus Toxins. June 23-25, 2005; Denver, CO, USA.

37. Trindade De Almeida A, de Boulle K. Diffusion characteristics of botulinum neurotoxin products and their clinical significance in cosmetic applications. J Cosmet Laser Ther. 2007;9(Suppl 1): $17-22$.

38. Hexsel D, Dal'Forno T, Hexsel C, do Prado DZ, Lima MM. A randomized pilot study comparing the action halos of two commercial preparations of botulinum toxin type A. Dermatol Surg. 2008;34(1): 52-59.

39. Cliff SH, Judodihardjo H, Eltringham E. Different formulations of botulinum toxin type A have different migration characteristics: a double-blind, randomized study. J Cosmet Dermatol. 2008;7(1): 50-54.

40. Hexsel D, Rodrigues TC, Soirefmann M, et al. Efficacy and field of effectiveness of two commercial preparations of botulinum toxin type A in the frontalis muscles - a double-blind, randomized and controlled study. [abstract] European Masters of Anti Aging Annual Conference; October 2-3, 2009; Paris, France.

41. Carruthers A, Carruthers J, Lowe NJ, et al; for the BOTOX ${ }^{\circledR}$ Glabellar Lines I and II Study Groups. One-year, randomised, multicenter, two-period study of the safety and efficacy of repeated treatments with botulinum toxin type A in patients with glabellar lines. J Clin Res. 2004; 7: $1-20$.

42. Dysport [package insert]. Brisbane, CA: Medicis Aesthetics Inc.;2009.

43. US Food and Drug Administration. Information for Healthcare Professionals: OnabotulinumtoxinA (marketed as Botox/Botox Cosmetic), AbobotulinumtoxinA (marketed as Dysport) and RimabotulinumtoxinB (marketed as Myobloc). http://www.fda.gov/Drugs/ DrugSafety/PostmarketDrugSafetyInformationforPatientsandProviders/ DrugSafetyInformationforHeathcareProfessionals/ucm174949.htm Accessed August 25, 2009.
44. US Food and Drug Administration. Follow-up to the February 8, 2008, Early Communication about an Ongoing Safety Review of Botox and Botox Cosmetic (Botulinum toxin Type A) and Myobloc (Botulinum toxin Type B). http://www.fda.gov/Drugs/ DrugSafety/PostmarketDrugSafetyInformationforPatientsandProviders/ DrugSafetyInformationforHeathcareProfessionals/ucm143819.htm. Accessed September 14, 2009.

45. Botox Cosmetic [package insert]. Irvine, CA: Allergan, Inc.; 2009.

46. Blitzer A, Binder WJ, Aviv JE, Keen MS, Brin MF. The management of hyperfunctional facial lines with botulinum toxin: a collaborative study of 210 injection sites in 162 patients. Arch Otolaryngol Head Neck Surg. 1997;123(4):389-392.

47. Wiest LG. An overview of the cosmetic treatment of facial muscles with a new botulinum toxin. Acta Dermatovenerol Croat. 2009;17(1): 48-53.

48. Ascher B, Zakine B, Kestemont P, Baspeyras M, Bougara A, Santini J. A multicenter, randomized, double-blind, placebo-controlled study of efficacy and safety of 3 doses of botulinum toxin A in the treatment of glabellar lines. J Am Acad Dermatol. 2004;51(2):223-233.

49. Monheit G, Carruthers A, Brandt F, Rand R. A randomized, doubleblind, placebo-controlled study of botulinum toxin type a for the treatment of glabellar lines: determination of optimal dose. Dermatol Surg. 2007;33(1 Spec No):S51-S59.

50. Carruthers A, Carruthers J. Long-term safety review of subjects treated with botulinum toxin type A for cosmetic use. [poster] Proceedings of the 13th Congress of the European Academy of Dermatology and Venereology; November 17-21, 2004; Florence, Italy.

51. Kawashima M, Harii K. An open-label, randomized, 64-week study repeating 10 - and $20-\mathrm{U}$ doses of botulinum toxin type A for treatment of glabellar lines in Japanese subjects. Int J Dermatol. 2009;48(7): 768-776.

52. Rzany B, Dill-Müller D, Grablowitz D, Heckmann M, Caird D. Repeated botulinum toxin a injections for the treatment of lines in the upper face: a retrospective study of 4,103 treatments in 945 patients. Dermatol Surg 2007;33(1 Spec No):S18-S25.

53. Monheit GD, Cohen JL; Reloxin Investigational Group. Long-term safety of repeated administrations of a new formulation of botulinum toxin type A in the treatment of glabellar lines: Interim analysis from an open-label extension study. J Am Acad Dermatol. 2009;61(3) 421-425.

54. Moy R, Maas C, Monheit G, Huber B; for the Reloxin Investigational Group. Long-term safety and efficacy of a new botulinum toxin type A in treating glabellar lines. Arch Facial Plast Surg. 2009;11(2):77-83.

55. Brin MF, Boodhoo TI, Pogoda JM, et al. Safety and tolerability of onabotulinumtoxinA in the treatment of facial lines: A meta-analysis of individual patient data from global clinical registration studies in 1678 participants. J Am Acad Dermatol. 2009;61(6):961-970.

56. Brandt F, Swanson N, Baumann L, Huber B. Randomized, placebocontrolled study of a new botulinum toxin type A for treatment of glabellar lines: efficacy and safety. Dermatol Surg. 2009;35:1893-1901.

57. Harii K, Kawashima M. A double-blind, randomized, placebocontrolled, two-dose comparative study of botulinum toxin type A for treating glabellar lines in Japanese subjects. Aesthetic Plast Surg. 2008;32(5):724-730.

58. Carruthers A, Carruthers J. Prospective, double-blind, randomized, parallel-group, dose-ranging study of botulinum toxin type A in men with glabellar rhytids. Dermatol Surg. 2005;31(10):1297-1303.

59. Carruthers A, Carruthers J, Said S. Dose-ranging study of botulinum toxin type A in the treatment of glabellar rhytids in females. Dermatol Surg. 2005;31(4):414-422.

60. Carruthers A, Carruthers J, Cohen J. Dilution volume of botulinum toxin type A for the treatment of glabellar rhytides: does it matter? Dermatol Surg. 2007;33(1 Spec No):S97-S104.

61. Grimes PE, Shabazz D. A four-month randomized, double-blind evaluation of the efficacy of botulinum toxin type A for the treatment of glabellar lines in women with skin types V and VI. Dermatol Surg. 2009;35(3):429-435. 
62. Rzany B, Ascher B, Fratila A, Monheit GD, Talarico S, Sterry W; for the GLADYS Study Group. Efficacy and safety of 3- and 5-injection patterns ( 30 and $50 \mathrm{U}$ ) of botulinum toxin A (Dysport) for the treatment of wrinkles in the glabella and the central forehead region. Arch Dermatol. 2006;142(3):320-326.

63. Kane MA, Brandt F, Rohrich RJ, Narins RS, Monheit GD, Huber MB; Relovin Investigational Group. Evaluation of variable-dose treatment with a new US botulinum toxin type A (Dysport) for correction of moderate to severe glabellar lines: results from a phase III, randomized, double-blind, placebo-controlled study. Plast Reconstr Surg. 2009;124(5)1619-1629.

64. Lowe P, Patnaik R, Lowe N. Comparison of two formulations of botulinum toxin type A for the treatment of glabellar lines: a double-blind, randomized study. J Am Acad Dermatol. 2006;55(6):975-980.

65. Ascher B, Zakine B, Kestemont P, et al. Botulinum toxin A in the treatment of glabellar lines: scheduling the next injection. Aesth Surg J. 2005;25:365-375

66. Cox SE, Finn JC, Stetler L, Mackowiak J, Kowalski JW. Development of the Facial Lines Treatment Satisfaction Questionnaire and initial results for botulinum toxin type A-treated patients. Dermatol Surg. 2003;29(5):444-449.

67. Stotland MA, Kowalski JW, Ray BB. Patient-reported benefit and satisfaction with botulinum toxin type A treatment of moderate to severe glabellar rhytides: results from a prospective open-label study. Plast Reconstr Surg. 2007;120(5):1386-1393.

68. Beer KR. Comparative evaluation of the safety and efficacy of botulinum toxin type A and topical creams for treating moderate-to-severe glabellar rhytids. Dermatol Surg. 2006;32(2):184-192.

69. Grimes PE. A four-month randomized, double-masked evaluation of the efficacy of botulinum toxin type A for the treatment of glabellar lines in women with skin types V and VI: Poster presented at: the 62nd Annual Meeting of the American Academy of Dermatology; February 6-11. 2004; Washington, DC.

70. Ellis DAF, Chi PL, Tan AKW. Facial rejuvenation with botulinum. Dermatol Nurs. 1997;9(5):329-333, 365.

71. Edwards CR, Teelucksingh S. Glycyrrhetinic acid and potentiation of hydrocortisone activity in skin. Lancet. 1990;336(8710):322-323.

72. De Boulle K. Patient satisfaction with different botulinum toxin type A formulations in the treatment of moderate to severe upper facial rhytids. $J$ Cosmet Laser Ther. 2008;10(2):87-92.

73. Draycott S, Dabbs A. Cognitive dissonance 1: An overview of the literature and its integration into theory and practice in clinical psychology. Br J Clin Psychol. 1998;37(Pt 3):341-353.

74. Kowalski J, Kozma C, Reese PR, Slaton T, Lee J. Initial development of a patient-completed questionnaire to assess outcomes of aesthetic treatment for hyperfunctional facial lines of the upper face. [poster] American Academy of Dermatology Academy's 2005 Annual Meeting; July 20-24, 2005; Chicago, Ill, USA.

75. Carruthers J, Carruthers A. Botulinum toxin type A treatment of multiple upper facial sites: patient-reported outcomes. Dermatol Surg. 2007;33(1 Spec No):S10-S17.

76. Fagien S, Cox SE, Finn JC, Werschler WP, Kowalski JW. Patient-reported outcomes with botulinum toxin type A treatment of glabellar rhytids: a double-blind, randomized, placebo-controlled study. Dermatol Surg. 2007;33(1 Spec No):S2-S9.
77. Sommer B, Zschocke I, Bergfeld D, Sattler G, Augustin M. Satisfaction of patients after treatment with botulinum toxin for dynamic facial lines. Dermatol Surg. 2003;29(5):456-460.

78. Carruthers J, Fagien S, Matarasso SL; and the Botox Consensus Group. Consensus recommendations on the use of botulinum toxin type A in facial aesthetics. Plast Reconstr Surg. 2004;114(Suppl 6):1S-22S.

79. Carruthers JDA, Glogau RG, Blitzer A; and the Facial Aesthetics Consensus Group Faculty. Advances in facial rejuvenation: botulinum toxin type A, hyaluronic acid dermal fillers, and combination therapies - consensus recommendations. Plast Reconstr Surg. 2008;121(Suppl 5):5S-30S.

80. Carruthers J, Carruthers A. A prospective, randomized, parallel group study analyzing the effect of BTX-A (Botox) and nonanimal sourced hyaluronic acid (NASHA, Restylane) in combination compared with NASHA (Restylane) alone in severe glabellar rhytides in adult female subjects: treatment of severe glabellar rhytides with a hyaluronic acid derivative compared with the derivative and BTX-A. Dermatol Surg. 2003;29(8):802-809.

81. Patel MP, Talmor M, Nolan WB. Botox and collagen for glabellar furrows: advantages of combination therapy. Ann Plast Surg. 2004;52(5):442-447.

82. Khoury JG, Saluja R, Goldman MP. The effect of botulinum toxin type A on full-face intense pulsed light treatment: a randomized, double-blind, split-face study. Dermatol Surg. 2008;1-8.

83. West TB, Alster TS. Effect of botulinum toxin type A on movementassociated rhytides following $\mathrm{CO}_{2}$ laser resurfacing. Dermatol Surg. 1999;25(4):259-261.

84. Yamauchi PS, Lask G, Lowe NJ. Botulinum toxin type A gives adjunctive benefit to periorbital laser resurfacing. J Cosmet Laser Ther. 2004;6(3):145-148.

85. Zimbler MS, Holds JB, Kokoska MS, et al. Effect of botulinum toxin pretreatment on laser resurfacing results: a prospective, randomized, blinded trial. Arch Facial Plast Surg. 2001;3(3):165-169.

86. Carruthers J, Carruthers A. The effect of full-face broadband light treatments alone and in combination with bilateral crow's feet botulinum toxin type A chemodenervation. Dermatol Surg. 2004;30(3): 355-366.

87. Carruthers J, Carruthers A. Complications of botulinum toxin type A. Facial Plast Surg Clin North Am. 2007;15(1):51-54, vi.

88. Krishtul A, Waldorf HA, Blitzer A. Complications of cosmetic botulinum toxin therapy. In: Carruthers A, Carruthers J, editors. Procedures in Cosmetic Dermatology Series: Botulinum Toxin. Philadelphia, PA; WB Saunders Company; 2005

89. American Society for Aesthetic Plastic Surgery. Cosmetic Surgery National Data Bank: 2008 Statistics. http://www.surgery.org/download/ 2008stats.pdf. Accessed March 17, 2009.

90. Tierney EP, Hanke CW. Recent trends in cosmetic and surgical procedure volumes in dermatologic surgery. Dermatol Surg. 2009;35(9): 1324-1333.
Clinical Interventions in Aging

\section{Publish your work in this journal}

Clinical Interventions in Aging is an international, peer-reviewed journal focusing on evidence-based reports on the value or lack thereof of treatments intended to prevent or delay the onset of maladaptive correlates of aging in human beings. This journal is indexed on PubMed Central, MedLine, the American Chemical Society's 'Chemical Abstracts Ser-

\section{Dovepress}

vice' (CAS), Scopus and the Elsevier Bibliographic databases. The manuscript management system is completely online and includes a very quick and fair peer-review system, which is all easy to use. Visit http://www.dovepress.com/testimonials.php to read real quotes from published authors. 